

\title{
Fire retardancy of ethylene-vinyl acetate composites - Evaluation of synergistic effects between ATH and diatomite fillers
}

Florian Cavodeau, Belkacem Otazaghine, Rodolphe Sonnier, José-Marie Lopez-Cuesta, Christelle Delaite

\section{To cite this version:}

Florian Cavodeau, Belkacem Otazaghine, Rodolphe Sonnier, José-Marie Lopez-Cuesta, Christelle Delaite. Fire retardancy of ethylene-vinyl acetate composites - Evaluation of synergistic effects between ATH and diatomite fillers. Polymer Degradation and Stability, 2016, 129, pp.246-259. 10.1016/j.polymdegradstab.2016.04.018 . hal-02906431

\section{HAL Id: hal-02906431 \\ https://hal.science/hal-02906431}

Submitted on 26 May 2021

HAL is a multi-disciplinary open access archive for the deposit and dissemination of scientific research documents, whether they are published or not. The documents may come from teaching and research institutions in France or abroad, or from public or private research centers.
L'archive ouverte pluridisciplinaire HAL, est destinée au dépôt et à la diffusion de documents scientifiques de niveau recherche, publiés ou non, émanant des établissements d'enseignement et de recherche français ou étrangers, des laboratoires publics ou privés. 


\title{
Fire retardancy of ethylene-vinyl acetate composites - Evaluation of synergistic effects between ATH and diatomite fillers
}

\author{
Florian Cavodeau ${ }^{a}$, Belkacem Otazaghine ${ }^{\text {a, }}{ }^{,}$, Rodolphe Sonnier ${ }^{\text {, }}$ \\ José-Marie Lopez-Cuesta ${ }^{\mathrm{a}}$, Christelle Delaite ${ }^{\mathrm{b}}$ \\ a Centre des Matériaux des Mines d'Alès (C2MA), 6 Avenue de Clavières, 30319, Alès Cedex, France \\ ${ }^{\mathrm{b}}$ Laboratoire de Photochimie et d'Ingénierie Macromoléculaires (LPIM), Institut Jean-Baptiste Donnet, 3bis Rue Alfred Werner, 68093, Mulhouse Cedex, \\ France
}

\begin{abstract}
A B S T R A C T
In the present work, diatomite was used as co-filler in aluminium hydroxide/ethylene-vinyl acetate composites (ATH/EVA). This silica-based marine sediment acts as a synergistic agent with ATH, to increase the flame retardant properties of EVA composites. When diatomite was used with ATH the formation of an expanded layer during cone calorimetry tests was observed. This layer presents a complex structure which better insulates the sample and reduces the heat release rate (HRR). Rheological measurements, such as complex viscosity obtained with an ARES apparatus, suggest an influence of the viscosity of the sample melt. We assume that the viscosity of the EVA composites is influenced by the porosity of the diatomite. Better residue cohesion was also obtained in presence of diatomite.
\end{abstract}

Keywords:

Flame retardancy

Barrier effect

ATH

EVA

Diatomite

\section{Introduction}

Ethylene-vinyl acetate (EVA) copolymers are commonly used in the cable industry, due to their properties and processing characteristics [1,2]. However, as the polymer decomposes under heat, the combustion gases can easily be ignited with enhanced fire risks. In order to meet fire performance standards, a large amount of fire retardant (FR) has to be introduced during the process [3]. In EVA copolymers, hydrated mineral fillers, such as aluminium trihydroxide (ATH) and magnesium dihydroxide $(\mathrm{MH})$ are widely used flame retardants at very high loadings (up to $65 \mathrm{wt} \%$ ) [4-7]. In the case of ATH, the endothermic degradation, which releases $34.6 \mathrm{wt} \%$ of water between 200 and $500{ }^{\circ} \mathrm{C}$, is the major fire retardant mechanism, leading to the cooling of the condensed phase and the dilution of flammable gases [8]. The high filler content also decreases the amount of flammable materials. The last major fire retardant mechanism is the barrier effect [9]. As the composite degrades during a fire, mineral fillers agglomerate at the surface, creating a protective layer. This layer limits the supply of the flame

\footnotetext{
* Corresponding author.

E-mail address: belkacem.otazaghine@mines-ales.fr (B. Otazaghine).
}

with gases of pyrolysis, and protects the underlying polymer from the heat flux $[5,10]$. The efficiency of the barrier effect depends on the thickness, the structure, but also the resistance of the layer. In a previous study, the barrier effect was estimated using the oedometric compression [11]. Many studies were carried out concerning the flame retardancy due to the expansion of polymers [12-17], but few ones have focused on mechanisms involved by the barrier effect $[9,18]$.

To enhance fire properties of a filled EVA, different additional flame retardant can be used as synergistic agents. These compounds improve the flame retardant properties of the composite by providing additional effects such as the formation of an expanded structure, a vitreous mineral layer at the surface of the material during thermal degradation $[19,20]$ or the modification of the degradation pathway of the polymer [21,22]. In the literature, silicabased compounds have been studied to improve the fire properties of polymers. These fillers, used in combination with fire retardant systems leading to expanded residues (EVA/MH/organoclay), increase the fire-proofing and the barrier effect $[12,23]$. The incorporation of only silica particles as synergistic agents with ATH was also studied [24,25], and the fire behaviour at high temperature seems to be improved by using fumed silica with a high surface area [24]. Other silica-based elements, such as diatomite (or calcined 
form of diatomaceous earth) did not receive attention as potential fire retardant filler. Diatomite is a siliceous sedimentary rock, composed of fossilized skeletons of diatoms, a type of single-celled algae $[26,27]$. It is generally used as filtration agent, abrasive or also as mechanical insecticide $[28,29]$. Skeletons of diatoms conserve the particular shape of algae, and develop a porous structure. Thousands of different species have been identified.

In this work, possible synergistic effects of a kind of diatomite on flame retardancy of EVA/ATH composites were investigated. In addition, the influence of the viscous behaviour of the composites at degradation temperatures was studied using an original flowing test.

\section{Experimental}

\subsection{Materials}

The EVA used was a thermoplastic-elastomeric grade Alcudia ${ }^{\circledR}$ PA-440 (Repsol), with a melt flow index of $7 \mathrm{~g} / 10 \mathrm{~min}\left(190{ }^{\circ} \mathrm{C}\right.$, $2.16 \mathrm{~kg}$ ) and a vinyl acetate content of $28 \mathrm{wt} \%$. Aluminium trihydroxide (ATH) SH20 was supplied by Alteo, with a median diameter $\left(D_{50}\right)$ of $2 \mu \mathrm{m}$ and obtained by grinding.

Diatomite used is a sedimentary rock extracted from a quarry located in Ardèche region (mountain of Andance), France. Species constituting the sediment are representative of an ancient fresh water environment, with their elongated frustule corresponding to pennates diatoms (the opposite of centric diatoms) [26]. Natural diatomite is mainly composed of silicon dioxide $\left(\mathrm{SiO}_{2}\right)$, but may also contain some impurities such as alumina $\left(\mathrm{Al}_{2} \mathrm{O}_{3}\right)$, calcium oxide $(\mathrm{CaO})$ or pyrite $\left(\mathrm{FeS}_{2}\right)$ [27]. Diatomite was crushed by a rotary mill to obtain a powder, with a measured $D_{50}$ of about $5 \mu \mathrm{m}$. A fraction of this crushed diatomite was then calcined at $1000^{\circ} \mathrm{C}$, leading to a sintering inside the particles, and to a crystallization of the silicon dioxide of its structure $[28,30]$.

A spherically-shaped amorphous silicon dioxide supplied by Elkem (Sidistar ${ }^{\circledR} \mathrm{T}-120$ ) was also used in composites. Another study, carried out in our laboratory by Sonnier et al. focused on Sidistar $^{\circledR}$ T-120 in EVA/ATH composites [31]. Fig. 1 represents SEM images of the Sidistar ${ }^{\circledR} \mathrm{T}-120$ and the diatomite used.

Table 1 presents some characteristics of the fillers. Powder true density was measured with a helium pycnometer AccuPyc 1330 (Micromeritics). Specific surface area ( $\mathrm{S}_{\mathrm{BET}}$ ) was measured by $\mathrm{N}_{2}$ adsorption at $77 \mathrm{~K}$ using a BET SA 3100 (Beckman-Coulter). Particle size $\left(D_{10}, D_{50}\right.$ and $\left.D_{90}\right)$ was measured with a laser diffraction particle size analyser LS 13320 (Beckman-Coulter), using an ultrasonic device to de-agglomerate particles.

There is an increase of powder true density of the diatomite after calcination, due to the crystallization of a part of the silicon dioxide.

\subsection{Processing}

Processing of composited was carried out by mixing the fillers with the molten EVA pellets using a twin-screw extruder (Clextral BC21, twin concave screws TCC, length $=900 \mathrm{~mm}$, speed $=200 \mathrm{rpm}$, screw diameter $=20 \mathrm{~mm}, \mathrm{~T}=80{ }^{\circ} \mathrm{C}-160{ }^{\circ} \mathrm{C}$ ). Then, $100 \times 100 \times 4 \mathrm{~mm}^{3}$ square sheets specimens were prepared using an injection moulding machine (Krauss-Maffei 50T-KM50/ $180 \mathrm{CX}$ ) at $140{ }^{\circ} \mathrm{C}$ under a pressure of 100 bars for $5 \mathrm{~min}$. All formulations are presented in Table 2.

Due to the apparent volume of the crushed diatomite, the extruder allows a maximum loading of $45 \%$ in EVA.

\subsection{Experimental techniques}

The maximum mass loss of samples was calculated by thermogravimetric analysis (TGA), using a Pyris 1 TGA (Perkin Elmer). The analyses were made under air, from 50 to $800^{\circ} \mathrm{C}$ at $10^{\circ} \mathrm{C} / \mathrm{min}$.

Fire performance was studied using a cone calorimeter apparatus (Fire Testing Technology - FTT) according to the standard ISO 5660 (sample dimensions $100 \times 100 \times 40 \mathrm{~mm}^{3}$ ). External heat flux was set to $50 \mathrm{~kW} / \mathrm{m}^{2}$. Time To Ignition (TTI), peak of Heat Release Rate (pHRR), Total Heat Release (THR), Effective Heat of Combustion (EHC) and Mass Loss were measured. The intensity of a second peak of Heat Release Rate at the end of the curve (pHRR2) was measured to estimate the barrier effect. Three samples were tested for each formulation with the cone calorimeter. In order to estimate the theoretical maximum THR, composites were analyzed by Pyrolysis Combustion Flow Calorimetry (PCFC) [32]. An anaerobic pyrolysis was performed with a FTT apparatus, with a heating rate of $1{ }^{\circ} \mathrm{C} / \mathrm{s}$. The maximum pyrolysis temperature was $750{ }^{\circ} \mathrm{C}$ and the combustion temperature was $900{ }^{\circ} \mathrm{C}$, corresponding to a complete combustion.

Dynamic rheological measurements were carried out to assess the change in complex viscosity using an ARES rheometer (Rheometric Scientific). The ARES (Advanced Rheometric Expansion System) is a mechanical spectrometer that enables to administrate a dynamic, or steady shear strain, deformation to a sample, and
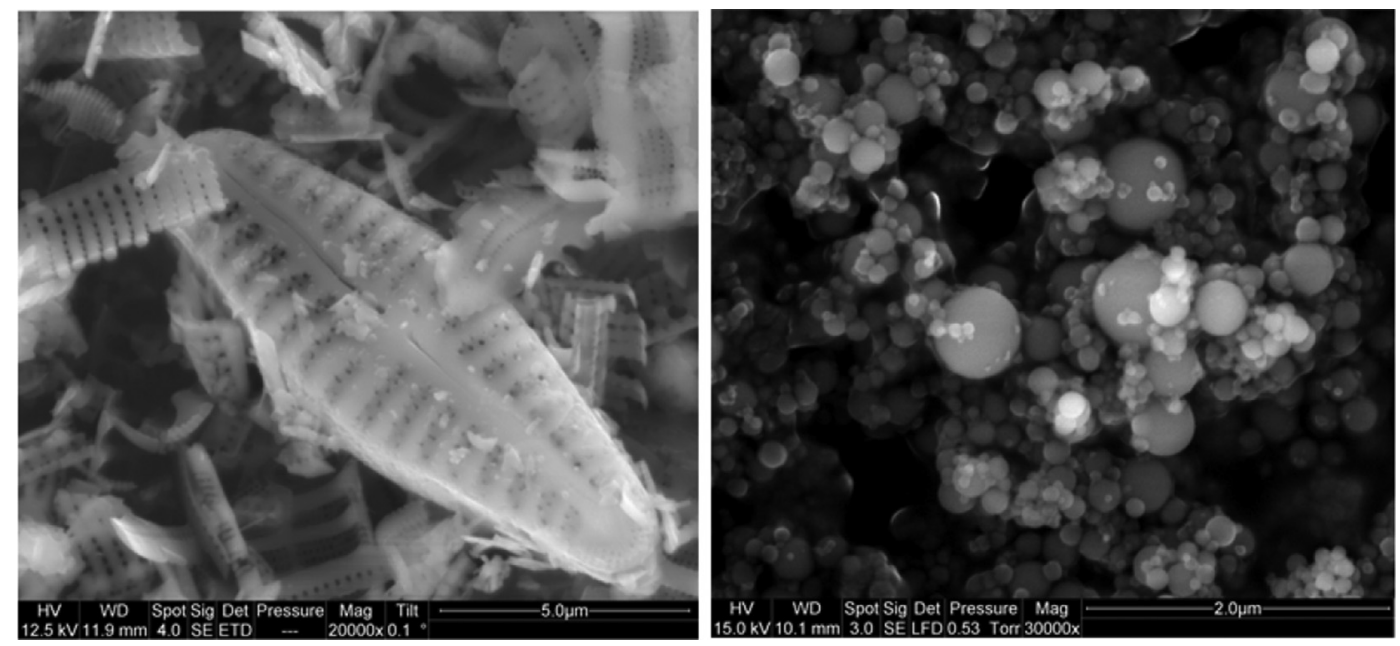

Fig. 1. Two silica-based structures by SEM: pennates diatoms (left-magnification $\times 20000$ ) and spherical silicon dioxide (right-magnification $\times 30000$ ). 
Table 1

Characteristics of fillers.

\begin{tabular}{|c|c|c|c|c|c|c|c|}
\hline Filler & Denomination & Powder true density $\left(\mathrm{g} / \mathrm{cm}^{3}\right)$ & $\mathrm{S}_{\mathrm{BET}}\left(\mathrm{m}^{2} / \mathrm{g}\right)$ & $\mathrm{D}_{10}$ Laser $(\mu \mathrm{m})$ & $\mathrm{D}_{50}$ Laser $(\mu \mathrm{m})$ & $\mathrm{D}_{90}$ Laser $(\mu \mathrm{m})$ & Mineral composition \\
\hline SH20 & A & 2.45 & 3.93 & 0.43 & 2.12 & 3.58 & $\mathrm{Al}(\mathrm{OH})_{3}$ \\
\hline Sidistar ${ }^{\circledR} \mathrm{T}-120$ & $\mathrm{~S}$ & 2.24 & 9.22 & 0.06 & 0.21 & 1.32 & $\mathrm{SiO}_{2}$ \\
\hline Crushed diatomite (raw) & $\mathrm{D}$ & 2.17 & 23.43 & 0.79 & 4.45 & 22.54 & $\mathrm{SiO}_{2}$ \\
\hline Crushed and calcinated diatomite & DC & 2.37 & 13.71 & 0.68 & 4.07 & 21.64 & $\mathrm{SiO}_{2}$ \\
\hline
\end{tabular}

Table 2

List of formulations.

\begin{tabular}{|c|c|c|c|c|c|}
\hline Formulation & EVA (wt\%) & SH20 (wt\%) & $\mathrm{T}-120(\mathrm{wt} \%)$ & Raw diatomite (wt\%) & Calcinated diatomite (wt\%) \\
\hline $60 \mathrm{~A}$ & 40 & 60 & - & - & - \\
\hline $50 \mathrm{~A} / 10 \mathrm{~S}$ & 40 & 50 & 10 & - & - \\
\hline $50 \mathrm{~A} / 10 \mathrm{DC}$ & 40 & 50 & - & - & 10 \\
\hline $55 \mathrm{~A} / 5 \mathrm{D}$ & 40 & 55 & - & 5 & - \\
\hline $50 \mathrm{~A} / 10 \mathrm{D}$ & 40 & 50 & - & 10 & - \\
\hline $45 \mathrm{~A} / 15 \mathrm{D}$ & 40 & 45 & - & 15 & - \\
\hline $45 \mathrm{D}$ & 55 & - & - & 45 & - \\
\hline EVA & 100 & - & - & - & - \\
\hline
\end{tabular}

then measuring the resultant torque in response to this deformation. This test enables to measure the viscoelastic properties of the sample, traduced by the complex viscosity $\left(\eta^{*}\right)$ and the elastic modulus $\left(\mathrm{G}^{\prime}\right)$. Viscoelasticity measurements were performed in oscillatory shear mode with parallel plate equipment at a fixed temperature of $160{ }^{\circ} \mathrm{C}$ using $0.5 \%$ strain and an angular frequency ranging from $0.1 \mathrm{rad} / \mathrm{s}$ to $100 \mathrm{rad} / \mathrm{s}$.

Some studies had already correlated the viscosity with the fire behaviour of polystyrene [33] and EVA composites [34] [35]. Experiments were made at a temperature corresponding to the molten state of the composite, before the thermal degradation of the material. However, as the temperature may reach the decomposition one of the polymer, its rheological evolution cannot be estimated using the ARES device. An alternative method must be found to follow the evolution of viscosity during cone calorimeter tests (ignition at approximately $450-500{ }^{\circ} \mathrm{C}$ for EVA, and with a surface layer of filled polymer reaching above $700-750{ }^{\circ} \mathrm{C}$ in the presence of the flame). A comparative observation of flowing composite under heat was made, using an epiradiator device. The epiradiator device is commonly used according to the French standard NF-P92-505. This standard corresponds to an experimental technique used to study the self-extinguishing aspect of a composite and the formation of flaming drops. In the present work, only the heating device was used, independently of the experimental technique described by the standard. Samples of $70 \times 70 \times 4 \mathrm{~mm}^{3}$ were exposed to a $500 \mathrm{~W}$ epiradiator, with an irradiance of $37 \mathrm{~kW} / \mathrm{m}^{2}$. As the temperature enhances with the time of exposure, the polymer flows through a $20 \times 20 \mathrm{~mm}^{2}$ hole, carved in a grid.

A laser pyrometer and a thermal camera were used to measure temperatures on each face of the sample during the test. Time to ignition, temperature to ignition and the difference of temperature between each face of the sample may be estimated. The whole device is represented on Fig. 2.

We assume that the speed of flowing depends on the variation of the apparent viscosity of the polymer with the heat. So, a polymer with a higher apparent viscosity at high temperature flows more slowly. During this test, the molten polymer forms a bulb through the grid. The apparent viscosity, or viscous behaviour, was estimated by following the duration of the flow of polymer until the falling of the bulb. The test and the formation of the bulb are represented on Fig. 3 and Fig. 4.

It is important to notice that the ignition occurs before the



Fig. 2. Epiradiator device with temperature measurement.

falling of the bulb, increasing mass loss due to the thermal decomposition and the speed of flowing.

\section{Results \& discussion}

\subsection{Calcination of diatomite}

The decrease of the accessible pore volume due to the calcination can be analyzed using the IUPAC classification of pore sizes [36]. Indeed, microporosity is considered for pore sizes smaller than $2 \mathrm{~nm}$, mesoporosity for sizes between 2 and $50 \mathrm{~nm}$, and macroporosity for sizes bigger than $50 \mathrm{~nm}$. Results obtained using the $\mathrm{BJH}$ (Barrett, Joyner and Halenda) method [37], are presented in Fig. 5. BJH method is used for porous solids to determine their poresize distribution. This method is based on the Kelvin equation and to a complete adsorption-desorption profile of nitrogen by the sample. Total measured pore volume reaches $0.065 \mathrm{~cm}^{3} / \mathrm{g}$ for raw diatomite and $0.038 \mathrm{~cm}^{3} / \mathrm{g}$ for the calcined form.

After the calcination of diatomite, the results show as expected a decrease of all categories of pores (micro, meso and macropores), 


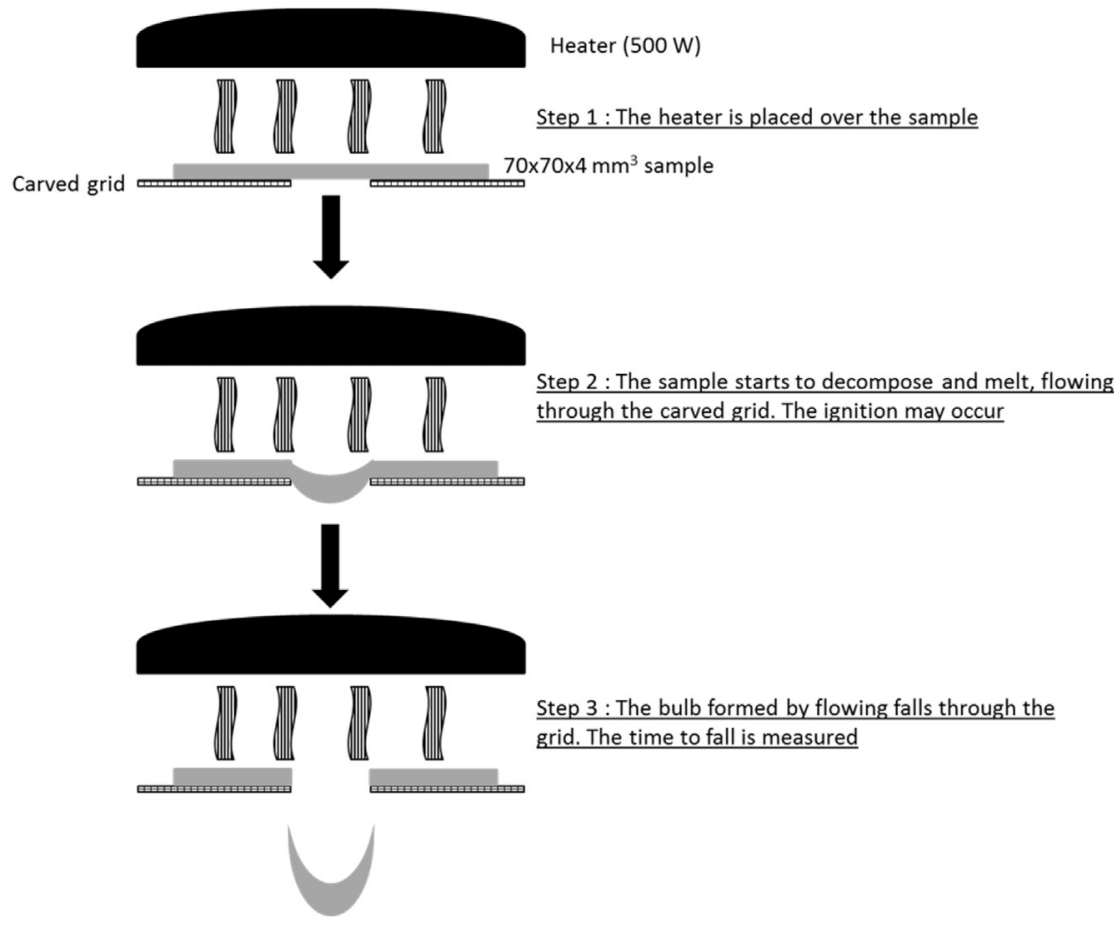

Fig. 3. Schematic representation of the flowing test using the epiradiator.

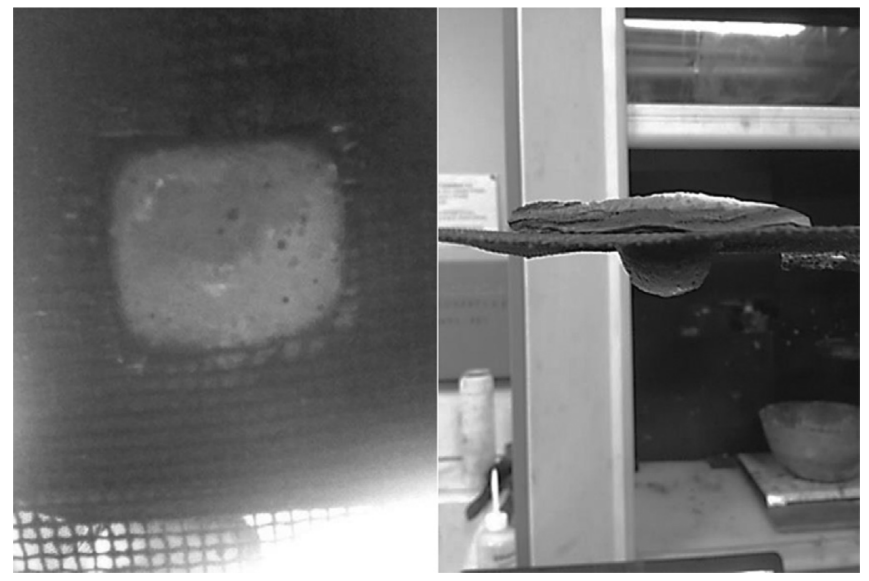

Fig. 4. Formation of a bulb of an EVA/ATH/diatomite composite through a carved grid.

and also for the total pore volume. This is also confirmed by a decrease of the measured specific surface area, corresponding to the decrease of the accessibility of pores.

A change of colour of the powder from grey to pale orange is also noticeable, corresponding to the transformation of pyrite $\left(\mathrm{FeS}_{2}\right)$ to hematite $\left(\mathrm{Fe}_{2} \mathrm{O}_{3}\right)$ [38]. The natural decomposition of organic parts initially present in diatomite may lead to impurities, such as pyrite, by a process named epigenesis [39]. In geology, the epigenesis corresponds to the transformation of chemical structures over time. This process is mainly applied to sedimentary mineral structures and may explain the presence of pyrite in the sample of diatomite [39]. The amount of pyrite is believed to be too low to have a significant influence (less than $1 \mathrm{wt} \%$ ), as presented in the EnergyDispersive X-ray spectroscopy (EDX) analysis in Table 3.

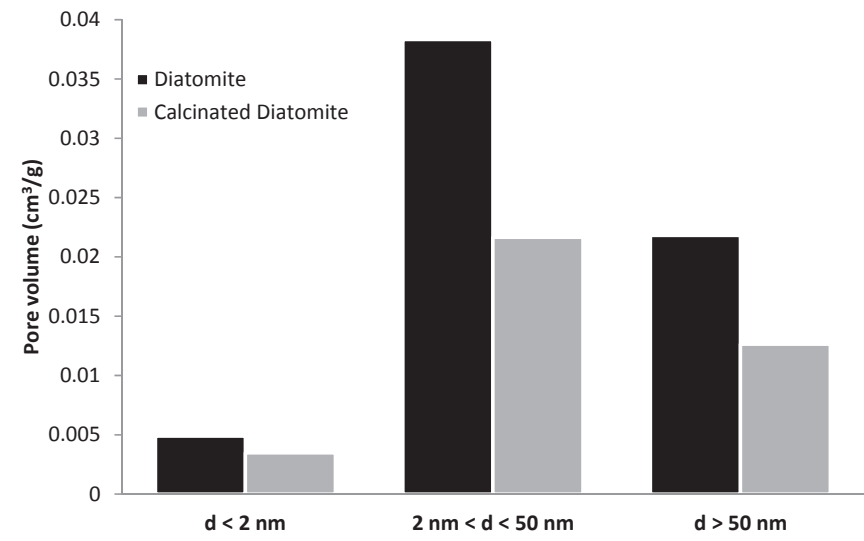

Fig. 5. Pore volumes of microporosity ( $d<2 \mathrm{~nm}$ ), mesoporosity ( $2 \mathrm{~nm}<\mathrm{d}<50 \mathrm{~nm}$ ) and macroporosity $(\mathrm{d}>50 \mathrm{~nm})$ of diatomite, before and after calcination. Results are estimated by the BJH method.

\subsection{Cone calorimeter results}

All results are presented in Table 4. HRR curves are presented on Fig. 6, Fig. 7 and Fig. 8. Theoretical maximum mass loss (or calculated mass loss) is determined by TGA analysis, to estimate the minimum residue rate theoretically present at the end of the cone calorimeter test. This mass loss was determined by calculation, based on the content of fillers for each sample and the mass loss due to the release of gases of decomposition, measured by TGA.

$$
\begin{aligned}
& \text { Calculated Mass Loss }=\left[\left(\text { Mass } \text { Loss }_{T G A} E V A\right) \times w t \%_{E V A}\right]+[ \\
& \left.\times\left(\text { Mass Loss }_{T G A} A T H\right) \times w t \%_{A T H}\right]+[ \\
& \times\left(\text { Mass } \text { Loss }_{\text {TGA }} \text { Silica }- \text { based filler }\right) \\
& \times w t \%_{\text {Silica-based filler }]}
\end{aligned}
$$


Table 3

EDX analysis of calcined and non-calcined diatomite.

\begin{tabular}{lcc}
\hline Element (\% weight) & Before calcination & After calcination \\
\hline $\mathrm{O}$ & 60.02 & 60.36 \\
$\mathrm{Al}$ & 0.59 & 0.60 \\
$\mathrm{Si}$ & 38.15 & 38.10 \\
$\mathrm{~S}$ & 0.39 & 0.08 \\
$\mathrm{Ca}$ & 0.19 & 0.19 \\
$\mathrm{Fe}$ & 0.66 & 0.67 \\
\hline
\end{tabular}

The presence of a high amount of ATH clearly reduces pHRR and improves fire properties, due to the water released (34.6 wt\%) from ATH and the dilution of EVA by the filler. Concerning the sample with $45 \%$ of raw diatomite (45D), pHRR is slightly reduced by the solid phase dilution and also by a barrier effect. It is interesting to notice that the ignition of the sample 45D occurs earlier than the ignition of the virgin EVA (29 s compared to 37 s). This may correspond to the catalysis of the thermal degradation of the

Table 4

Results of cone calorimeter tests.

\begin{tabular}{|c|c|c|c|c|c|c|c|c|}
\hline Formulation & TTI (s) & $\mathrm{pHRR}\left(\mathrm{kW} / \mathrm{m}^{2}\right)$ & pHRR2 $\left(\mathrm{kW} / \mathrm{m}^{2}\right)$ & THR $(\mathrm{kJ} / \mathrm{g})$ & $\mathrm{THR}^{\mathrm{a}}$ theo $\max (\mathrm{kJ} / \mathrm{g})$ & $\mathrm{EHC}(\mathrm{MJ} / \mathrm{kg})$ & Mass loss (\%) & Calculated Mass loss ${ }^{\mathrm{b}}(\%)$ \\
\hline $60 \mathrm{~A}$ & 43 & 208 & 138 & 18.0 & 20.0 & 28.4 & 59.6 & 60.5 \\
\hline $50 \mathrm{~A} / 10 \mathrm{~S}$ & 54 & 242 & 104 & 14.3 & 20.8 & 25.1 & 58.4 & 58.6 \\
\hline $50 \mathrm{~A} / 10 \mathrm{DC}$ & 56 & 221 & 92 & 13.0 & 21.5 & 26.4 & 57.8 & 57.7 \\
\hline $55 \mathrm{~A} / 5 \mathrm{D}$ & 46 & 199 & 87 & 15.1 & 19.8 & 25.3 & 57.7 & 59.0 \\
\hline $50 \mathrm{~A} / 10 \mathrm{D}$ & 54 & 152 & 67 & 11.3 & 21.5 & 23.8 & 50.6 & 57.8 \\
\hline $45 \mathrm{~A} / 15 \mathrm{D}$ & 54 & 145 & 88 & 12.2 & 21.2 & 24.9 & 47.6 & 56.0 \\
\hline $45 \mathrm{D}$ & 29 & 668 & 237 & 23.4 & 26.5 & 32.0 & 53.5 & 54.7 \\
\hline EVA & 37 & 810 & - & 43.3 & 43.4 & 34.4 & 100 & 100 \\
\hline
\end{tabular}

${ }^{\text {a }}$ Values obtained using PCFC analysis.

b Values calculated using TGA analysis.

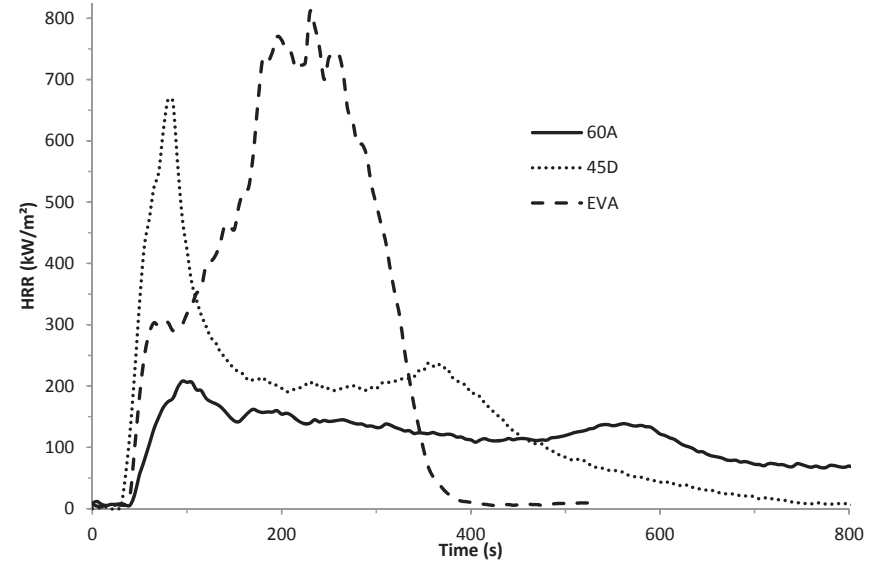

Fig. 6. Cone calorimeter tests for EVA/ATH and EVA/Diatomite composites, compared to pure EVA (Heat flux: $50 \mathrm{~kW} / \mathrm{m}^{2}$ ).

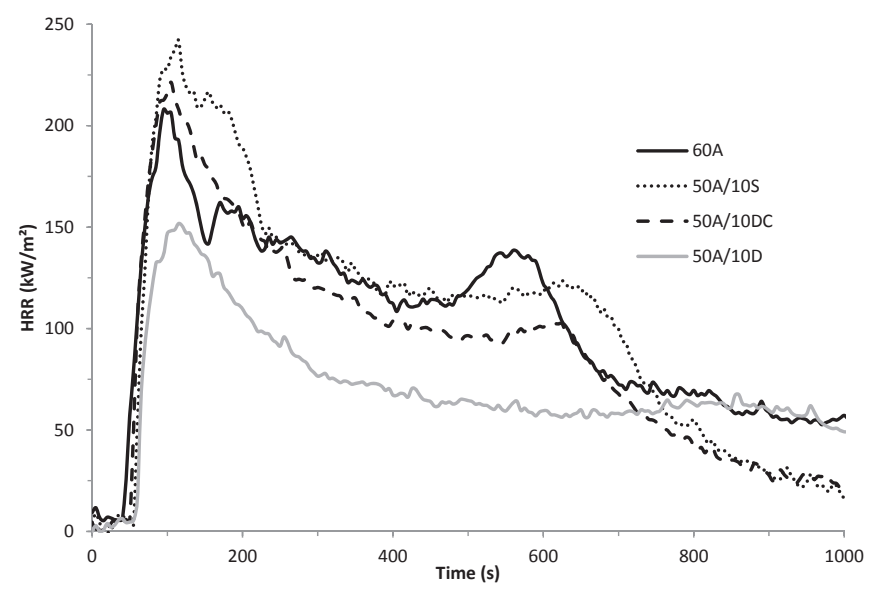

Fig. 7. Cone calorimeter tests for composites containing $10 \%$ of silica-based particles (Heat flux: $50 \mathrm{~kW} / \mathrm{m}^{2}$ ).

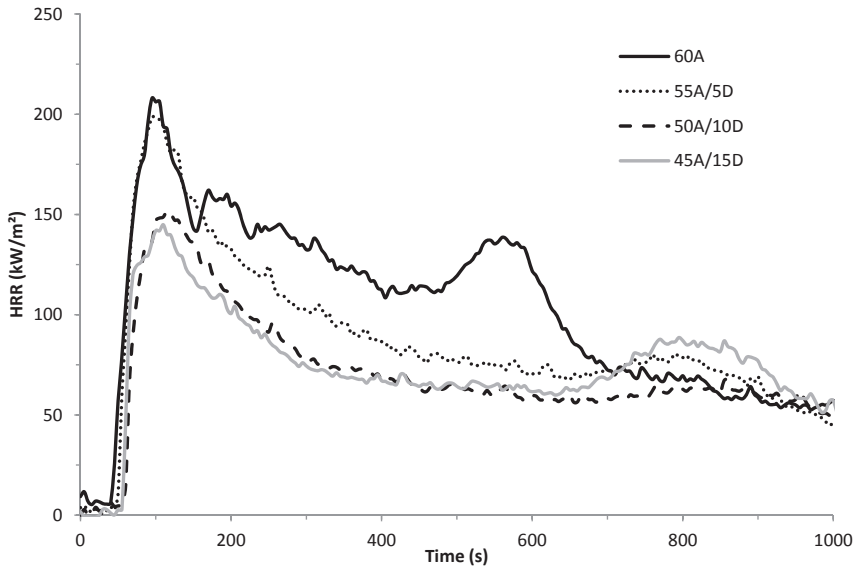

Fig. 8. Cone calorimeter tests for EVA/ATH/Diatomite composites (Heat flux: $50 \mathrm{~kW} /$ $\mathrm{m}^{2}$ ).

polymer. This aspect will be discussed in the part 3.5. Concerning the barrier effect, the curve presents a second pHRR at $350 \mathrm{~s}$ after a progressive decrease, characteristic of the degradation of the barrier layer. The creation of the barrier layer can also be visualized by the formation of a foamed-like residue. The residue is thicker and more cohesive than with $60 \mathrm{wt} \%$ of ATH. The structure presents cavities, like a solid foam (see Fig. 9). A THR of $23.4 \mathrm{~kJ} / \mathrm{g}$ is measured. This value is slightly lower than the THR measured by PCFC, of $25.4 \mathrm{~kJ} / \mathrm{g}$. The difference also confirms the action of a barrier effect during the test, slowing the degradation.

By substituting 5 wt\% of ATH by raw diatomite in an EVA/ATH composite, the pHRR is not highly reduced (Fig. 8). However, the THR reaches a value of $15.1 \mathrm{~kJ} / \mathrm{g}$, whereas the EVA/ATH of reference reaches a value of $18.0 \mathrm{~kJ} / \mathrm{g}$. The sample with $5 \mathrm{wt} \%$ of diatomite (55A/5D) also leads to the formation of an expanded structure. With $10 \mathrm{wt} \%$ of raw diatomite (50A/10D), pHRR reaches $152 \mathrm{~kW} / \mathrm{m}^{2}$ and the THR is $11.3 \mathrm{~kJ} / \mathrm{g}$. As the sample 60A presents a pHRR of $208 \mathrm{~kW} / \mathrm{m}^{2}$, the incorporation of $10 \%$ of raw diatomite clearly reduced the first pHRR. The decrease of pHRR and THR confirms the presence of an efficient barrier effect, which slows down the 

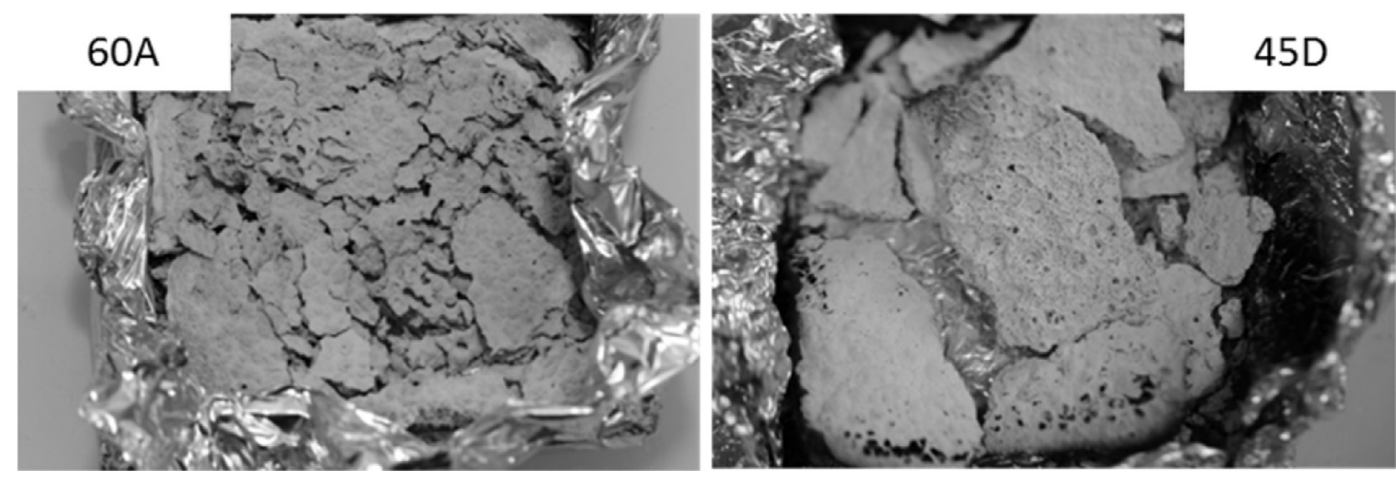

Fig. 9. Residues of cone calorimeter tests of the sample $60 \mathrm{~A}$ and the sample $45 \mathrm{D}$.

degradation and prevents the entire decomposition of the polymer. The swelling of the sample is also more important during the test, leading to thicker residue. When $15 \mathrm{wt} \%$ of raw diatomite are introduced $(45 \mathrm{~A} / 15 \mathrm{D})$, the reduction of pHRR is slightly less important $\left(145 \mathrm{~kW} / \mathrm{m}^{2}\right)$, and the swelling of the sample under the cone calorimeter is more intense. Contrary to the expectations, THR reaches $12.2 \mathrm{~kJ} / \mathrm{g}$, which is higher than the sample with $10 \mathrm{wt} \%$ of diatomite. This reflects a less efficient barrier effect for this sample, confirmed by the presence of an earlier second pHRR. As mentioned in a previous study [11], the appearance of a second pHRR is related to the cracking of the layer formed during the fire. Furthermore, it seems that the intensity of this peak is correlated to its time of appearance. For the sample $45 \mathrm{~A} / 15 \mathrm{D}$, a higher pressure of the gases of decomposition is assumed to cause the early cracking of the expanded structure. The cracking is noticeable on macroscopic scale and an optimal performance was found for a composite containing $50 \mathrm{wt} \%$ of ATH and $10 \mathrm{wt} \%$ of crushed diatomite.

All these results show that the combination of both fillers is important for the improvement of flame retardancy properties. This improvement is due to the formation of a more cohesive residue during sample degradation. No expansion was observed for the sample 45D in absence of ATH. This proves the need to have both fillers to obtain a good barrier effect and to improve the HRR value. Water released by ATH and gases from the decomposition of EVA generated an expansion of the residue structure. Moreover, the diffusion of gases through the layer is reduced, thus corresponding to a lower pHRR.

The organization of fillers was observed at the end of the cone test for the EVA/ATH/Diatomite composite, showing a homogeneous dispersion of both fillers in the residue (see Table 5). SEM images, analyzed with EDX, show the dispersion of $\mathrm{ATH}$ and $\mathrm{Al}_{2} \mathrm{O}_{3}$ by pointing out the element aluminium ( $\mathrm{Al})$, and the dispersion of diatomite through this of silicon $(\mathrm{Si})$.

In the composite before cone calorimeter test, dispersion of diatomite seems to be rather good, while the dispersion of ATH seems to be less homogeneous, as agglomerates are clearly present. Moreover, better dispersion is observed for diatomite. For the sample analyzed after the cone calorimeter test, particles are organized as a compact layer. However, the dispersion is more homogeneous, with the absence of any agglomerate of $\mathrm{Al}_{2} \mathrm{O}_{3}$.

In comparison with raw diatomite $\left(152 \mathrm{~kW} / \mathrm{m}^{2}\right)$, the sample filled with $10 \mathrm{wt} \%$ of calcined diatomite shows a higher pHRR value $\left(221 \mathrm{~kW} / \mathrm{m}^{2}\right)$. Furthermore, the sample does not lead to an expanded structure (see Fig. 10). The presence of calcined diatomite does not change the fire behaviour of the EVA/ATH composite. The same observation is done for the sample containing $10 \mathrm{wt} \%$ of a spherically-shaped amorphous silicon dioxide (sample 50A/10S with Sidistar $\left.{ }^{\circledR} \mathrm{T}-120\right)$. A higher pHRR is obtained $\left(242 \mathrm{~kW} / \mathrm{m}^{2}\right)$, even if the residue seems to be slightly expanded, as presented in Fig. 10. In the work of Sonnier et al. [31], a significant synergistic effect was found between the Sidistar ${ }^{\circledR}$ T-120 and an ATH (OL-104 LEO-Martinswerk). pHRR measured at cone calorimeter test (irradiance: $50 \mathrm{~kW} / \mathrm{m}^{2}$ ) for similar EVA/ATH composites (50 wt\% SH20/ $10 \mathrm{wt} \%$ Sidistar ${ }^{\circledR}$ T-120 in the present work and $51 \mathrm{wt} \%$ OL-104 LEO/ $9 \mathrm{wt} \%$ Sidistar $^{\circledR} \mathrm{T}-120$ in the work of Sonnier et al. [31]) is very close (about $250 \mathrm{~kW} / \mathrm{m}^{2}$ ). However, the barrier effect seems to be better for the sample containing OL-104 LEO. Indeed, compared to a sample containing only the $\mathrm{ATH}$, there is a disappearance of the second pHRR with the substitution of $9 \mathrm{wt} \%$ of OL-104 LEO with Sidistar ${ }^{\circledR} \mathrm{T}-120$. The improvement of the barrier effect described by Sonnier et al. [31] may be influenced by the shape, the texture or also the state of dispersion of the ATH used in combination with the silicon dioxide filler.

Regarding the results obtained with samples 50A/10DC, 50A/ $10 \mathrm{D}$ and $50 \mathrm{~A} / 10 \mathrm{~S}$, it seems that the porosity of the silica-based filler is one of the most important parameter controlling the formation of an expanded structure. As the calcination of diatomite reduces the measured specific surface area, the accessibility of the porous structure influences the efficiency of the fire retardancy.

\subsection{Influence of viscosity on fire retardancy (ARES rheometer)}

Better performances for EVA/ATH/Diatomite composites in cone calorimeter tests seem to be attributed to an efficient barrier effect. The formation of a cohesive layer was attributed to the release of gases in a structure allowing the expansion. A high viscosity of the molten composite during the cone test may be a coherent explanation. Indeed, the influence of the rheology of EVA composites on their fire retardancy was already suggested by Clerc et al. [34]. The authors proposed that the swelling of EVA/Magnesium hydroxide/ Talc composites could depend on the viscous behaviour of material, and may influence the thickness of the residue. They suggested that the use of talc particles of high specific surface area can enhance the expansion process. A comparison was made with EVA/Magnesium hydroxide/Organomodified montmorillonite (oMMT) composites which also provide a significant expansion, which could be called mineral intumescence. When the content of oMMT is too high, the viscosity may become too high and may prevent the expansion. The thermal insulation due to the barrier layer seems to be reduced by the absence of swelling of the residue. Observations made by Kashiwagi et al. [33] correlate the increase of the elastic modulus $\left(G^{\prime}\right)$, measured by rheometric measurements, with the formation of a cohesive charred layer of polystyrene nanocomposites. According to the authors, a too weak viscosity of the composite may have an influence on an early cracking of the barrier layer. 
Table 5

SEM/EDX cartography of the elements $\mathrm{Al}$ and $\mathrm{Si}$ in the sample $50 \mathrm{~A} / 10 \mathrm{D}$ (magnification $\times 1000$ ).

\begin{tabular}{|c|c|c|c|}
\hline & SEM images & Al dispersion & Si dispersion \\
\hline Composite before cone calorimeter & & 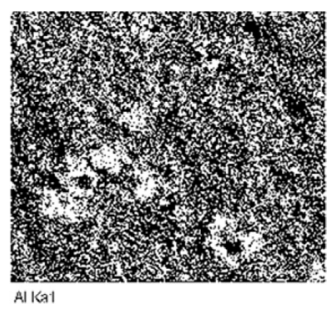 & $\begin{array}{l}\text { sika1 } \\
\text { Si }\end{array}$ \\
\hline Residue after cone calorimeter & & 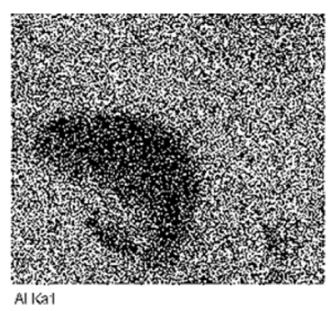 & 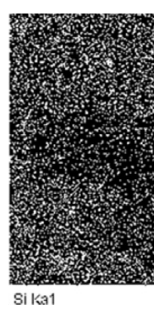 \\
\hline
\end{tabular}
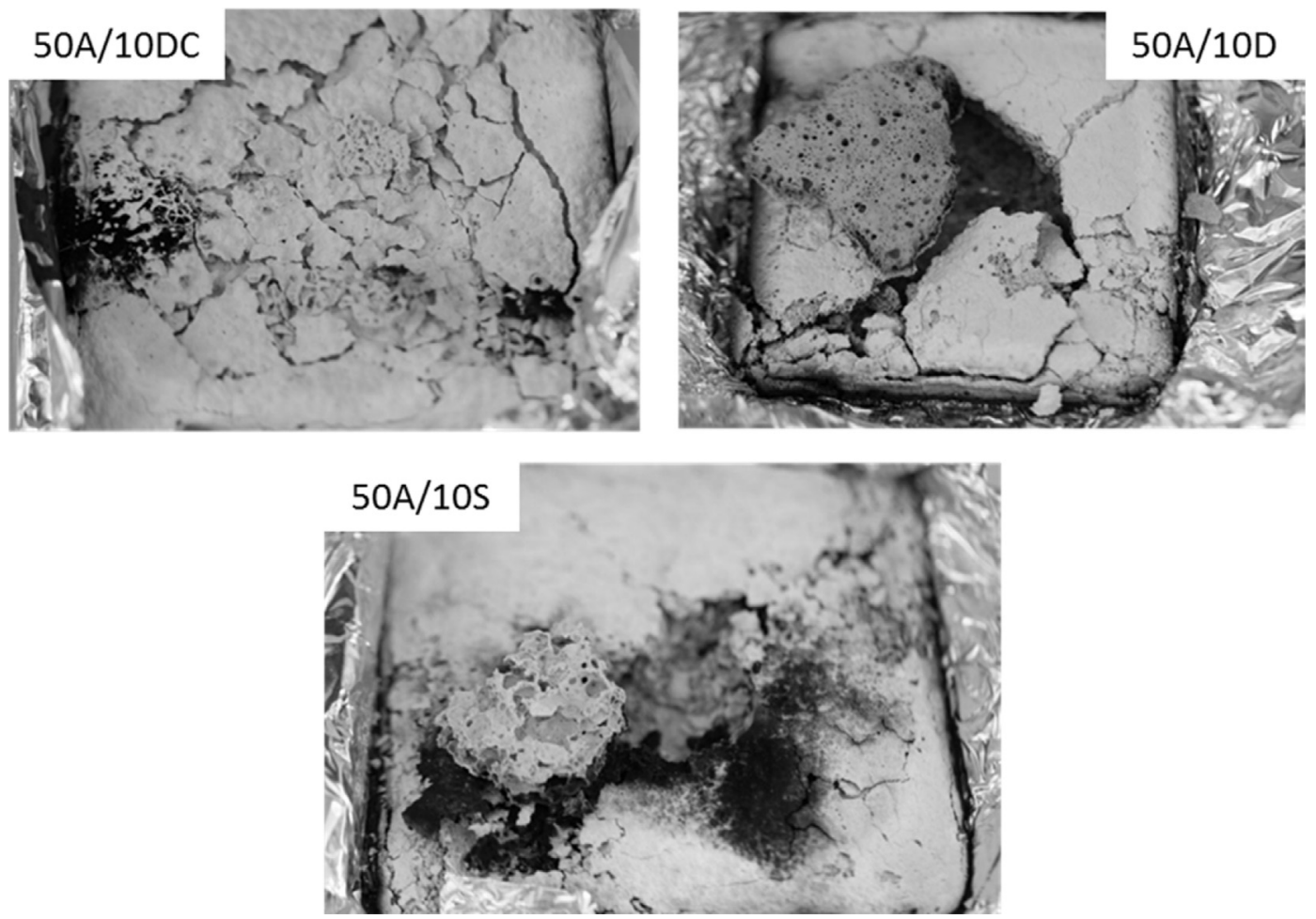

Fig. 10. Residues of cone calorimeter tests of the sample 50A/10DC, the sample $50 \mathrm{~A} / 10 \mathrm{D}$ and the sample $50 \mathrm{~A} / 10 \mathrm{~S}$

Batistella et al. showed that the viscosity of EVA/Kaolinite composites has an influence on the efficiency of the flame retardancy [35]. The authors assumed that bubbles resulting from composite decomposition are limited when the viscosity of the melt samples is high. This phenomenon limits the supply of the flame with the gases of pyrolysis. They showed correlations between the rheology of composites containing ATH or Kaolinite and the value of pHRR. Parameters such as apparent complex viscosity $\left(\eta^{*}\right)$, elastic modulus $\left(G^{\prime}\right)$ and tangent $(\delta)$ were studied using an ARES rheometer. A recent study of Batistella et al. [40] focuses on the influence of the dispersion of the kaolinite on the fire retardant mechanisms. According to the authors, it seems that a higher viscosity is reached when the dispersion of the filler is optimal, leading to an improved fire behaviour. The microstructure of the particles seems to be an important parameter influencing the state of dispersion in the matrix.

Similar ARES analyses were carried out in the present study on EVA/ATH/silica-based fillers samples, regarding the intensity of pHRR. Fig. 11 presents the results of complex viscosity obtained for all samples, except the sample 45D which contains $45 \mathrm{wt} \%$ of diatomite. Indeed, the sample $45 \mathrm{D}$ seems to have a too high viscosity, as the analysis does not present a Newtonian plateau [41]. 


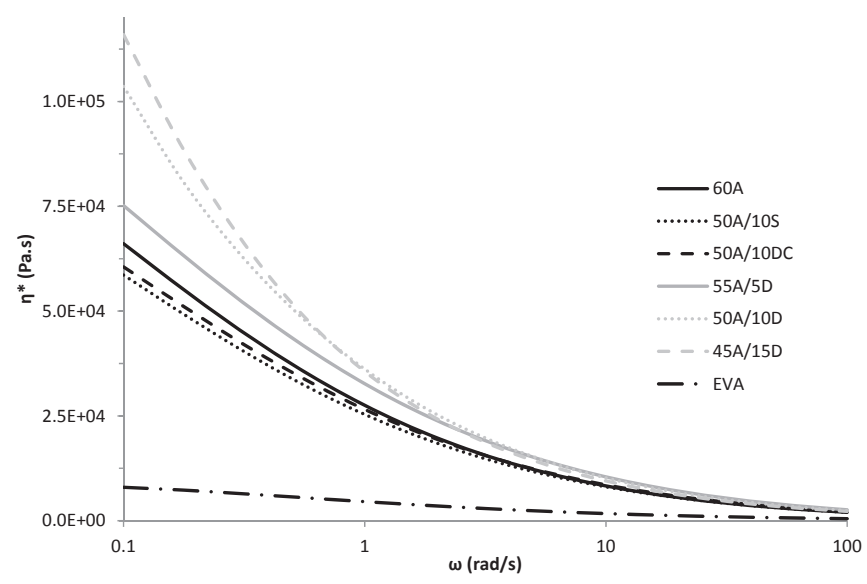

Fig. 11. Complex viscosity $\eta^{*}$ (Pa s) of EVA/ATH/silica-based fillers composites.

Complex viscosity decreases for all samples with the frequency. In comparison to the neat polymer, $\eta^{*}$ values of composites are higher. The curves seem to reach a minimum value of about $2000 \mathrm{~Pa} s$ at a frequency of $100 \mathrm{rad} / \mathrm{s}$, for all the tested formulations. The introduction of calcined diatomite entails a decrease of the viscosity of the EVA/ATH composite, whereas the introduction of at least $5 \mathrm{wt} \%$ of raw diatomite increases this value compared to the $60 \mathrm{~A}$ composition.

Values of pHRR for the different composites were plotted as a function of the complex viscosity, at a frequency of $0.1 \mathrm{rad} / \mathrm{s}$ (named $\eta^{*}{ }_{0}$ ) (Fig. 12). Measurement of $\eta^{*}{ }_{0}$ for the sample 45D is also presented, even if it remains a measurement uncertainty related to this value due to the absence of a Newtonian plateau.

Viscosities of composites are estimated with $\eta^{*}{ }_{0}$. When the viscosity increases, pHRR decreases until reaching a minimal value. This minimum corresponds to the sample $45 \mathrm{~A} / 15 \mathrm{D}$, with pHRR value of $144.89 \mathrm{~kW} / \mathrm{m}^{2}$. The increase of the samples viscosity corresponds to a more efficient flame retardancy. The role of the viscosity proposed by Batistella et al. [35] was related to the flame supply with gases of decomposition, limited by the decrease of bubbling.

In comparison with the results obtained in the study of Batistella et al. [35], the trend of the influence of the viscosity on the pHRR seems to be confirmed. The measurements carried out with the ARES rheometer were compared using the elastic modulus $\left(\mathrm{G}^{\prime}\right)$ of the different formulations. Regarding the dynamic behaviour of the composites at $0.1 \mathrm{rad} / \mathrm{s}$, the elastic modulus $\left(\mathrm{G}^{\prime}\right)$ and the complex viscosity $\left(\eta^{*}\right)$ are related, as the viscoelasticity of the samples is

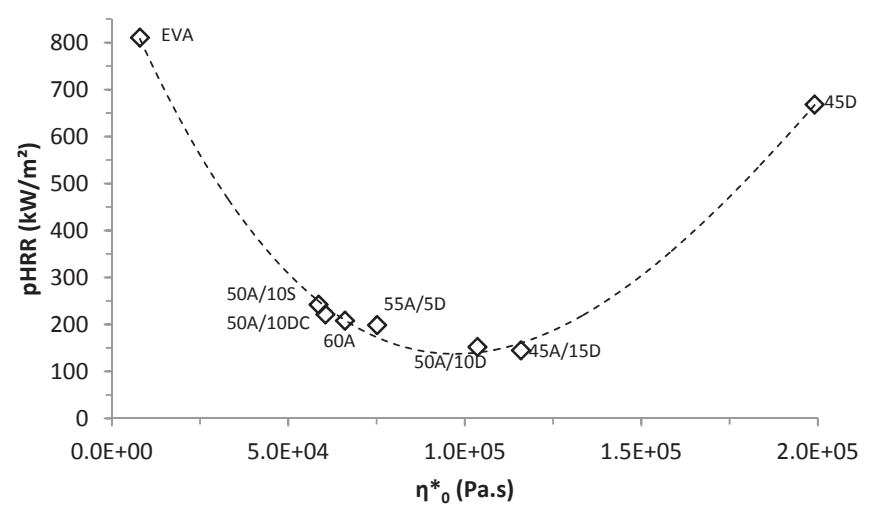

Fig. 12. pHRR versus the complex viscosity at a frequency of $0.1 \mathrm{rad} / \mathrm{s}\left(\eta^{*}{ }_{0}\right)$. linear at low frequencies. Fig. 13 presents the relation $\mathrm{G}^{\prime} / \mathrm{G}^{\prime} \mathrm{EVA}$

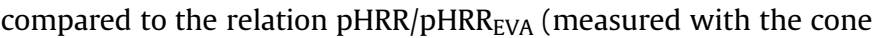
calorimeter) for the formulations studied in this work compared to the results obtained in the study of Batistella et al. [35].

Almost all of the measurements made on the composites containing diatomite match the results obtained by Batistella et al. The authors described two distinct tendencies. In the Regime 1, the relation $\mathrm{pHRR} / \mathrm{pHRR}_{\mathrm{EVA}}$ decreases quickly from 1 to 0.2 when the relation $G^{\prime} / G^{\prime}$ EVA increases from 1 to 5 . After a relative elastic modulus of about $5-10$, a second regime is observed (called Regime 2 ). In this regime, the relative pHRR of the samples remains almost constant, close to $0.2-0.3$. An increase is however present for some samples with a higher $\mathrm{G}^{\prime}$. In the case of EVA composites, the viscosity seems to have a certain influence on the efficiency of the rheological barrier, by slowing down the bubbling and the thermal convection during cone calorimeter tests. However, the data corresponding to the formulation $45 \mathrm{D}$ is out of the trend, as the composite does not present a significative fire retardant improvement. This point will be discussed later.

Regarding the results obtained with diatomite, it seems that the viscosity influence the formation of the barrier layer during the second part of the cone calorimeter curve, after pHRR. For low viscosities (including the sample 60A), the protective layer does not expand during the cone test, and a less efficient barrier effect is obtained. This is traduced by an experimental THR of $18.0 \mathrm{~kJ} / \mathrm{g}$, which is close to the maximum theoretical value of $20.0 \mathrm{~kJ} / \mathrm{g}$. For high viscosities (i.e. the sample 55A/5D, 50A/10D and 45/15D, containing respectively 5,10 and $15 \mathrm{wt} \%$ of diatomite), an expansion is observed, corresponding to an efficient barrier effect. For these samples, the THR measured with the cone calorimeter test is respectively of $15.1,11.3$ and $12.2 \mathrm{~kJ} / \mathrm{g}$. These values are lower than the maximum theoretical ones, of respectively 19.8, 21.5 and $21.2 \mathrm{~kJ} / \mathrm{g}$. The decrease of the THR, associated with the increase of the amount of residual material at the end of the cone calorimeter test, may traduce a more efficient barrier effect.

In order to study the barrier effect, it was proposed in a previous work to focus on the appearance of a second pHRR at the end of the cone calorimeter curve [11]. Indeed, the presence of a second pHRR (called pHRR2) is expected to correspond to the cracking of the barrier layer, related to its resistance and stability, and the release of all the remaining gases of decomposition. It was already shown that the intensity of the pHRR2 can be related to its time of appearance. So, a more efficient barrier effect can be traduced by a late and weak pHRR2. Fig. 14 presents the values of the pHRR2 for all samples except 45D and pure EVA as function of the complex viscosity at a frequency of $0.1 \mathrm{rad} / \mathrm{s}\left(\eta^{*}{ }_{0}\right)$.

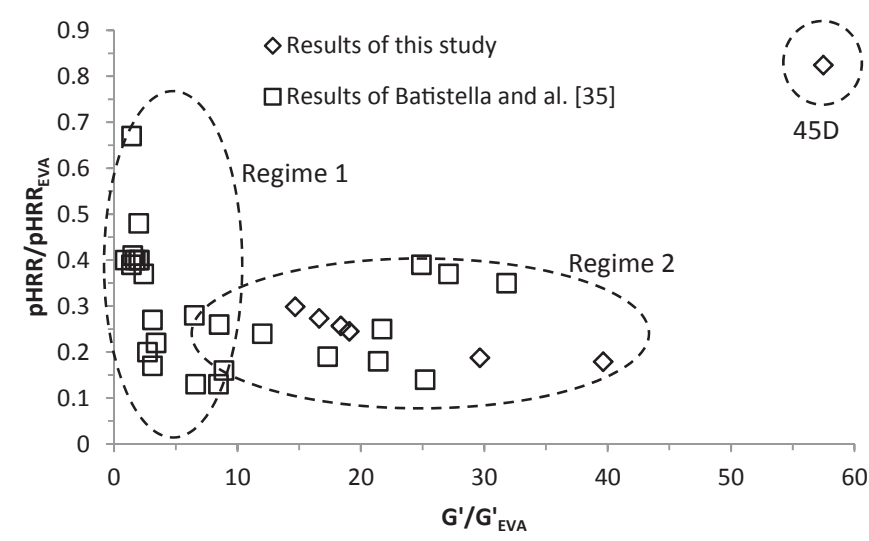

Fig. 13. Comparison of the results obtained is this study with the measurements carried out by Batistella et al. [35]. 


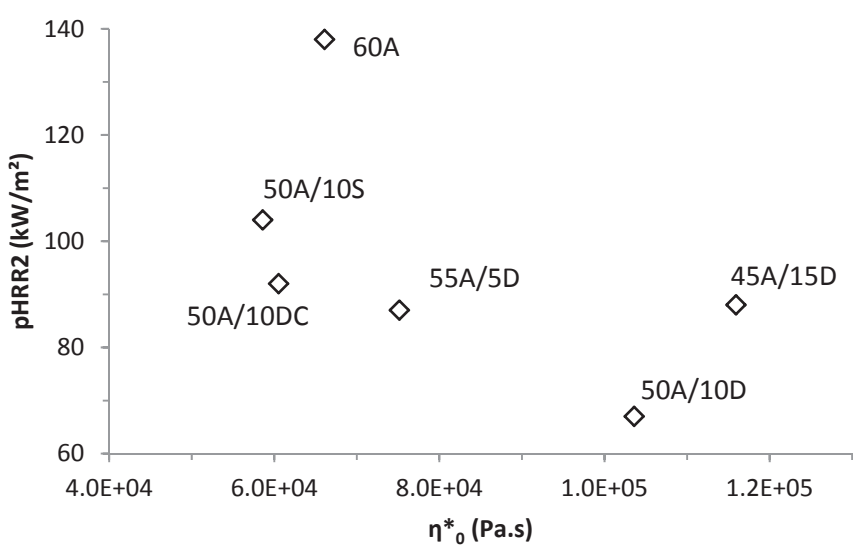

Fig. 14. pHRR2 versus the complex viscosity at a frequency of $0.1 \mathrm{rad} / \mathrm{s}\left(\eta^{*}{ }_{0}\right)$.

Regarding the values of pHRR2, the sample 60A seems to be out of the trend compared to the samples containing silica-based fillers. The sample $60 \mathrm{~A}$ does not lead to a residual structure composed of cavities, as a solid foam, compared to the other formulations (Figs. 9 and 10.). For the samples containing silica-based fillers, pHRR2 is quickly reduced when the complex viscosity increases from about 58600 (sample 50A/10S) to 60500 Pa s (sample 50A/10DC). After this limit, the decrease seems to be slow and progressive while the viscosity increases. Around a complex viscosity of $100000 \mathrm{~Pa} \mathrm{~s}$, a minimum seems to be reached, corresponding to the sample $50 \mathrm{~A} /$ 10D, with a pHRR2 of $67 \mathrm{~kW} / \mathrm{m}^{2}$. After this limit, the increase of viscosity corresponds to a higher value of pHRR2. The sample 45A/ $15 \mathrm{D}$ traduces this observation, as the pHRR2 reaches $88 \mathrm{~kW} / \mathrm{m}^{2}$.

In the case of the samples leading to an expansion, the increase of viscosity can be related to the capacity of the formulations to limit the release and retain the gases of decomposition. Up to a viscosity of about $100000 \mathrm{~Pa}$ s, the barrier effect provided by the expansion results in the reduction of the heat release for the second part of the cone calorimeter curve. For higher viscosities, it is assumed that the strong resistance of the barrier layer prevents the release of gases of decomposition. The accumulation of gases under the barrier layer enhances the expansion, forcing the cracking.

It was first presented that a high viscosity slows down the kinetics of the release of gases, resulting in the reduction of the bubbling at the surface of the sample. This influence was noticed on cone calorimeter curves from pHRR value. In the second part of the cone calorimeter curve, a high viscosity enables the creation and the expansion of a barrier layer. From a certain value, the capacity of expansion seems to be too strong to provide an efficient flame retardancy. As the viscosity of the formulations may be a common parameter of these two phenomena, the reduction of the bubbling may have an influence on the expansion of the barrier layer.

\subsection{Influence of viscosity on fire retardancy (flowing at high temperature)}

Measurements carried out with the ARES rheometer were made at $160{ }^{\circ} \mathrm{C}$. This temperature is far lower than the temperature of the sample during a cone calorimeter test, generally around $700-750{ }^{\circ} \mathrm{C}$ at $50 \mathrm{~kW} / \mathrm{m}^{2}$ (measured using a laser pyrometer). An estimation of the samples viscous behaviour at $700-750{ }^{\circ} \mathrm{C}$ is needed to validate our hypothesis.

The measurement of the flow of molten composites during their thermal degradation may be a way to estimate roughly their viscosity. Our method is based on the principle of the Melt Flow Index (MFI), without applying any force [42]. Another major difference is that, during the MFI measurement, the sample is homogeneously heated, whereas a heating cone irradiates one face of the material. So, there is a thermal gradient along the sample during its degradation, with a heterogeneous distribution of the temperature.

The viscosity at high temperature was estimated using a radiative heat device called epiradiator. During the fire test, the melt composite flows through a grid at a certain speed. Comparison between the samples gives a classification according to their estimated apparent viscosities. The apparatus is presented in Fig. 2.

Table 6 contains measured parameters such as the Fall Time of the bulb; Time to ignition and temperature at ignition (upper surface). The description of samples and residues is also presented.

Samples leading to residues with a solid-foamed structure present a fall time equal or higher to $385 \mathrm{~s}$ (including the samples that do not fall during the test), and no bubbling. For samples $45 \mathrm{~A} /$ $15 \mathrm{D}$ and $45 \mathrm{D}$, the bulb remains attached to the rest of the polymer at the end of the test. The absence of fall, even after 15 min of irradiation, traduces a higher apparent viscosity than for the other samples.

Samples 50A/10S and 50A/10DC flow more quickly through the hole of the grid, as the molten sample falls after $220-230 \mathrm{~s}$. The reference sample (60A) falls after 310 s of irradiance, but presents a bubbling at the surface, and flaming drops. Their residues from cone tests present a fragile and non-cohesive structure. The mineral fillers form a thin layer with a weak protective aspect.

It seems that a higher fall time, corresponding to a higher apparent viscosity during the fire test, can be related to disappearance of the bubbling at the surface of samples and to the formation of an expanded residue, except for the sample 45D. The comparison with the complex viscosity $\eta^{*}{ }_{0}$ obtained by ARES analyses, shows the same ranking for the fall time of the samples, as presented on Fig. 15.

The efficiency of the barrier effect seems to depend on the structure formed during the fire. A layer with an expanded solid foam structure provides an efficient fire retardancy. The formation of this kind of structure needs a sufficient viscosity to be obtained. On the contrary, low viscosity leads to a thin and non-cohesive structure with limited barrier effect. The absence of bubbling during the epiradiator test may be related also to a high viscosity which limits the release of decomposition gases.

The measurement of temperatures during the epiradiator test shows the same evolution for all samples. On upper surface, a quick enhancement first occurs when the epiradiator is set upon the samples. This is followed by a pseudo-linear evolution until the ignition. At this point, a strong and instantaneous increase occurs, characterized on the curve by a clear temperature transition from $450-500{ }^{\circ} \mathrm{C}$ to $600-650{ }^{\circ} \mathrm{C}$. Then, the temperature of the upper surface tends to a maximum of about $750{ }^{\circ} \mathrm{C}$, with little evolution.

On the lower surface of the samples, the temperature follows a more non-linear profile until the falling of the composite. Measurements are not relevant after the falling of the bulb because of the presence of a large hole at the center of the sample. Results are presented in Table 7.

Samples presenting better results during cone calorimeter tests ignite at a higher temperature than samples presenting poor fire retardancy. The temperature evolution is roughly the same for both sides. Temperature measurements seem to follow the same ranking as ARES rheometer results and fall time.

\subsection{Catalytic effect of the diatomite}

Cone calorimeter tests on the sample 45D presents a lower TTI than pure EVA. Indeed, the composite 45D ignites at $29 \mathrm{~s}$, while the TTI of pure EVA is $37 \mathrm{~s}$. Other formulations ignite between 43 and $56 \mathrm{~s}$. Moreover, the formulation 45D does not follow the same trend 
Table 6

Measurements with epiradiator device.

\begin{tabular}{|c|c|c|c|c|}
\hline Formulation & Fall Time (s) & Time to ignition (s) & Temperature at ignition $\left({ }^{\circ} \mathrm{C}\right)$ & Observations \\
\hline $60 \mathrm{~A}$ & 310 & 90 & 440 & $\begin{array}{l}\text { - Bubbling at the surface } \\
\text { - Flaming drops } \\
\text { - Fragile and non-cohesive residue }\end{array}$ \\
\hline $50 \mathrm{~A} / 10 \mathrm{~S}$ & 219 & 105 & 460 & $\begin{array}{l}\text { - Bubbling at the surface } \\
\text { - Flaming drops } \\
\text { - Fragile and slightly structured residue }\end{array}$ \\
\hline $50 \mathrm{~A} / 10 \mathrm{DC}$ & 230 & 105 & 470 & $\begin{array}{l}\text { - Bubbling at the surface } \\
\text { - Flaming drops } \\
\text { - Fragile and non-cohesive residue }\end{array}$ \\
\hline $55 \mathrm{~A} / 5 \mathrm{D}$ & 385 & 95 & 480 & $\begin{array}{l}\text { - Absence of bubbling } \\
\text { - Expanded residue (solid foam) }\end{array}$ \\
\hline $50 \mathrm{~A} / 10 \mathrm{D}$ & 500 & 105 & 485 & $\begin{array}{l}\text { - Absence of bubbling } \\
\text { - Expanded residue (solid foam) }\end{array}$ \\
\hline $45 \mathrm{~A} / 15 \mathrm{D}$ & - & 110 & 485 & $\begin{array}{l}\text { - Absence of bubbling } \\
\text { - The bulb remains attached to the sample } \\
\text { - Expanded residue (solid foam) }\end{array}$ \\
\hline $45 \mathrm{D}$ & - & 70 & 500 & $\begin{array}{l}\text { - Absence of bubbling } \\
\text { - The bulb remains attached to the sample } \\
\text { - Formation of a solid foam without expansion }\end{array}$ \\
\hline EVA & - & 60 & - & $\begin{array}{l}\text { - Too liquid at high temperature for a measurement (intense dropping) } \\
\text { - Absence of residue }\end{array}$ \\
\hline
\end{tabular}

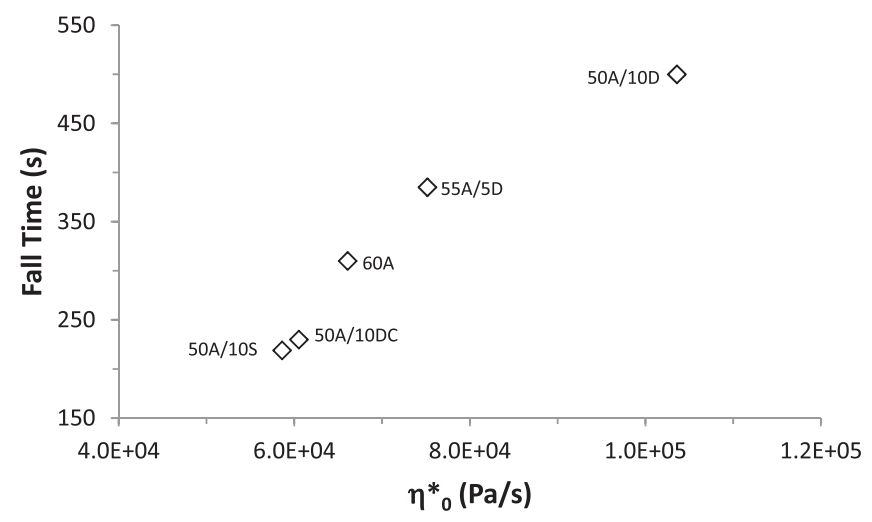

Fig. 15. Fall Time versus the complex viscosity at a frequency of $0.1 \mathrm{rad} / \mathrm{s}\left(\eta^{*}{ }_{0}\right)$. water. At $300{ }^{\circ} \mathrm{C}$, a second decomposition step occurs, corresponding to the elimination of the acetic acid of the matrix. For the composite 45D, the thermal decomposition begins at $200{ }^{\circ} \mathrm{C}$ and goes on until the degradation step of the main chain of the polymer, at $420{ }^{\circ} \mathrm{C}$. This step seems to be also moved forward, knowing that the degradation of the main chain of EVA and the sample 60A occurs at $400{ }^{\circ} \mathrm{C}$. This variation may correspond to an enhancement of the stability of the polymeric structure formed after the degradation of the pendant groups.

All composites containing diatomite present the same thermal decomposition profile. First, the release of water is moved forward of about $10{ }^{\circ} \mathrm{C}$, and then, the thermal degradation seems to be progressive until the step corresponding to the residues. The early degradation of the EVA at $200{ }^{\circ} \mathrm{C}$ for the sample 45 is absent for the other samples.

Table 7

Temperature values measured during epiradiator test using laser pyrometer (upper surface) and thermal camera (lower surface).

\begin{tabular}{|c|c|c|c|}
\hline Formulation & Temperature to ignition - upper surface $\left({ }^{\circ} \mathrm{C}\right)$ & Temperature to ignition - lower surface $\left({ }^{\circ} \mathrm{C}\right)$ & Temperature at the falling - lower surface $\left({ }^{\circ} \mathrm{C}\right)$ \\
\hline $60 \mathrm{~A}$ & 440 & 170 & 235 \\
\hline $50 \mathrm{~A} / 10 \mathrm{~S}$ & 460 & 180 & 330 \\
\hline $50 \mathrm{~A} / 10 \mathrm{DC}$ & 470 & 190 & 330 \\
\hline $55 \mathrm{~A} / 5 \mathrm{D}$ & 480 & 190 & 340 \\
\hline $50 \mathrm{~A} / 10 \mathrm{D}$ & 485 & 190 & 350 \\
\hline $45 \mathrm{~A} / 15 \mathrm{D}$ & 485 & 190 & - \\
\hline $45 \mathrm{D}$ & 500 & 220 & - \\
\hline EVA & - & - & - \\
\hline
\end{tabular}

than other ones concerning the influence of viscosity. TGA curves obtained for all formulations are presented in Figs. 16-19. TGA analyses were made under air, from 50 to $800{ }^{\circ} \mathrm{C}$ at $10{ }^{\circ} \mathrm{C} / \mathrm{min}$. These experimental conditions correspond to an aerobic pyrolysis, similar to the degradation of the composite until the ignition during a fire. DTG curves are also presented, in order to visualize the degradation steps of the samples.

The degradation of the sample $60 \mathrm{~A}$ begins at $250{ }^{\circ} \mathrm{C}$, while the pure EVA starts to decompose at $300{ }^{\circ} \mathrm{C}$, corresponding to the release of acetic acid. The difference of the temperature of beginning of the degradation for the formulation $60 \mathrm{~A}$ seems to be due to the presence of $\mathrm{ATH}$, and corresponds to the release of structural
According to Fig. 19, the calcination of diatomite removes the beginning of the decomposition observed at $200{ }^{\circ} \mathrm{C}$. In order to precise the catalytic effect of the raw diatomite on the degradation of EVA, a sample filled with $45 \mathrm{wt} \%$ of calcined diatomite was prepared and analyzed by TGA (this formulation is called 45DC). In the case of the sample 45DC, the first step of the thermal degradation occurs at a similar temperature than the sample 60A. The catalytic effect of the diatomite seems to disappear after the calcination.

The analysis of the formulations with a pyrolysis combustion flow calorimetry (PCFC) was made, with an infrared analysis coupling (IRTF) [43]. Results enable to identify the products of the 

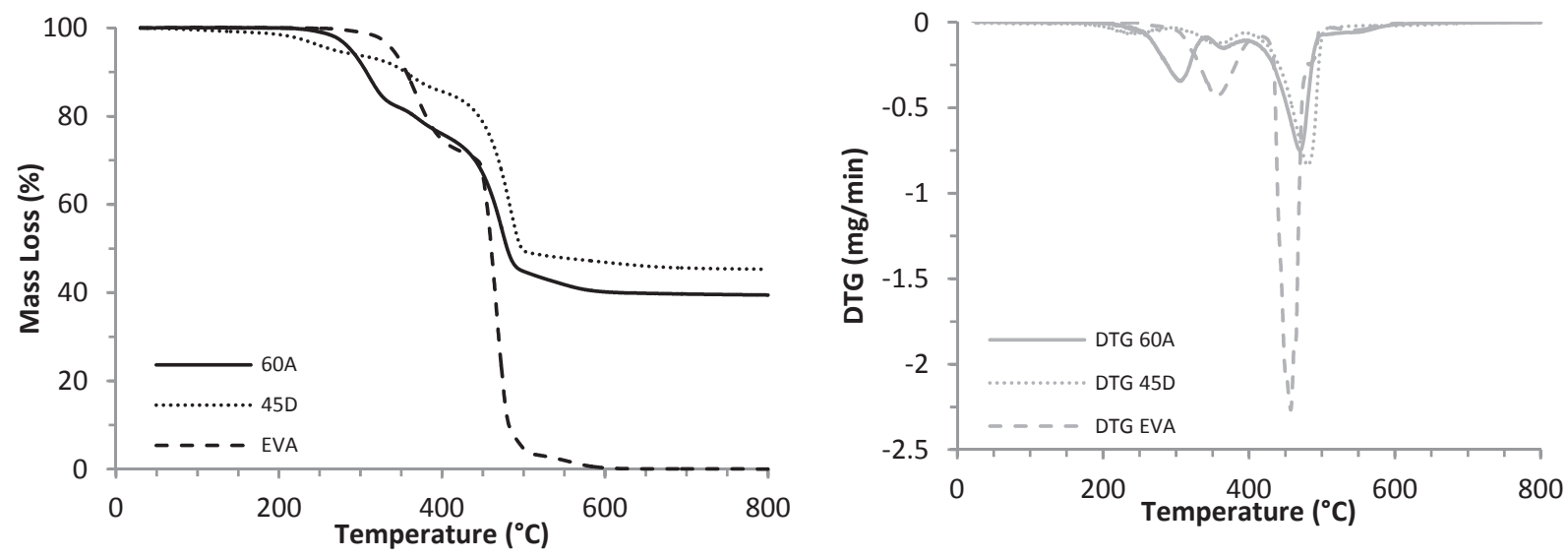

Fig. 16. TGA (left)-DTG (right) measurements of $60 \mathrm{~A}$ and $45 \mathrm{D}$ samples (compared to pure EVA).
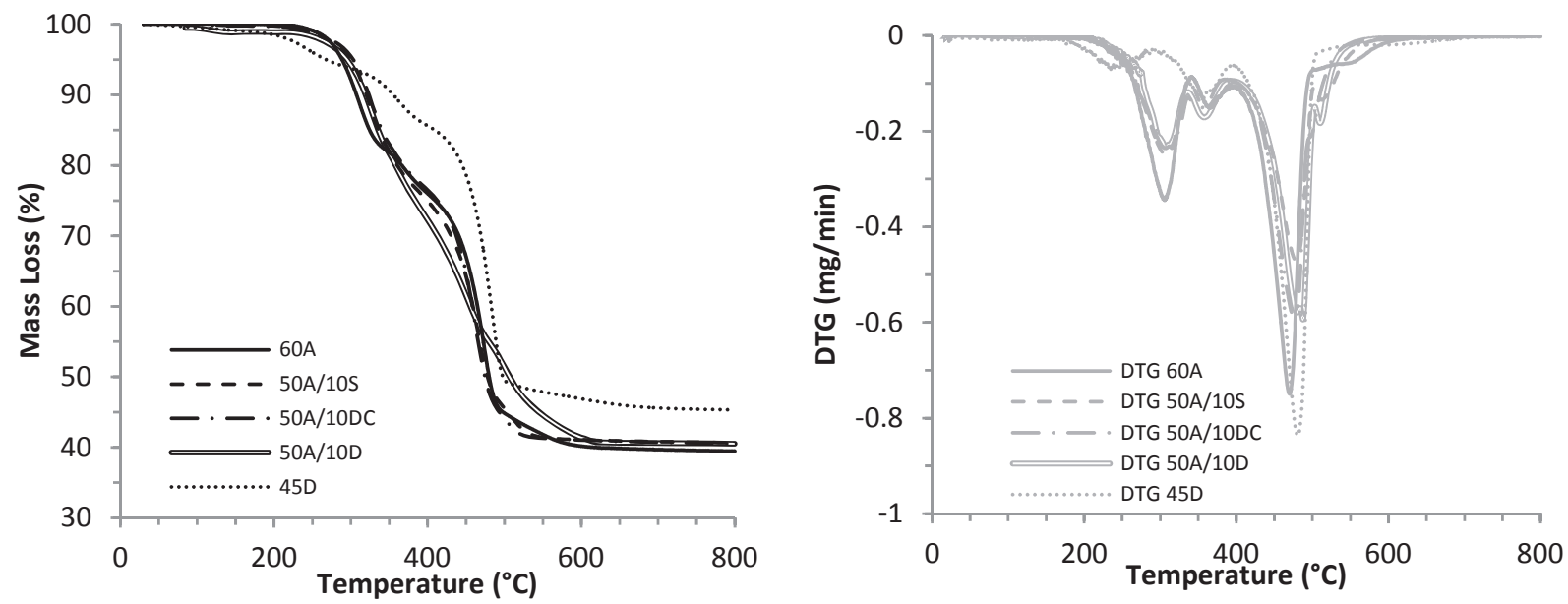

Fig. 17. TGA (left)-DTG (right) of the composites containing $10 \mathrm{wt} \%$ of silica-based fillers.
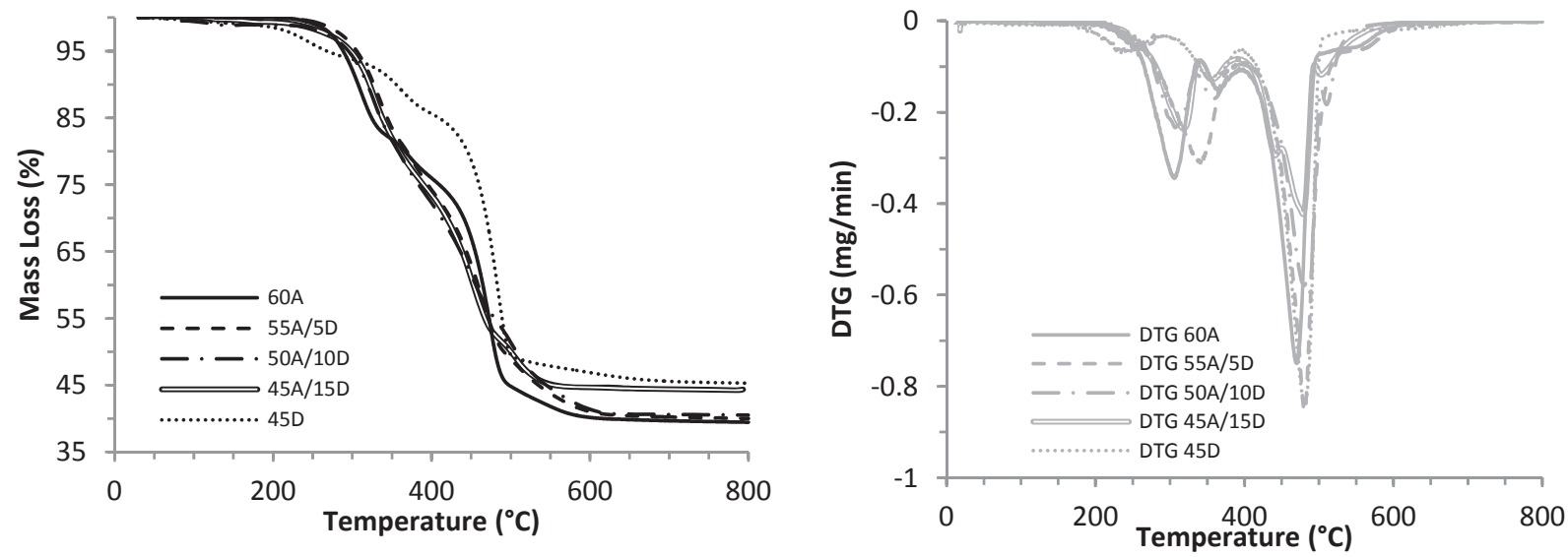

Fig. 18. TGA (left)-DTG (right) of the composites containing raw diatomite.

combustion of gases of pyrolysis (Fig. 20 and Fig. 21).

The introduction of a high rate of fillers in the EVA logically enables the decrease of the heat release during the thermal degradation. pHRR of the EVA and the sample 60A appear at a similar temperature (of about $475{ }^{\circ} \mathrm{C}$ ), while the pHRR of the sample 45D seems to appear earlier (of about $455{ }^{\circ} \mathrm{C}$ ). For the samples $60 \mathrm{~A}$ and EVA, the beginning of the heat release seems to occur at $300-350{ }^{\circ} \mathrm{C}$, while the formulation $45 \mathrm{D}$ presents an appearance of heat release at $200{ }^{\circ} \mathrm{C}$.

PCFC measurements of all samples are presented on Fig. 21. Compared to the other formulations, the sample 45D degrades at a lower temperature, as already presented on Fig. 18. The first 




Fig. 19. TGA curves of the composites $60 \mathrm{~A}, 45 \mathrm{D}$ and $45 \mathrm{DC}$.

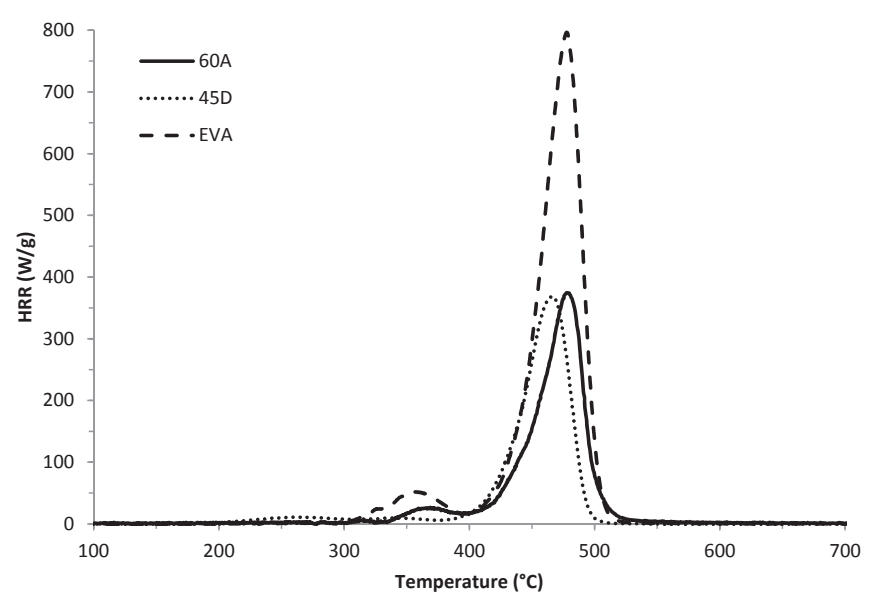

Fig. 20. PCFC curves of the samples 60A, 45D and pure EVA.

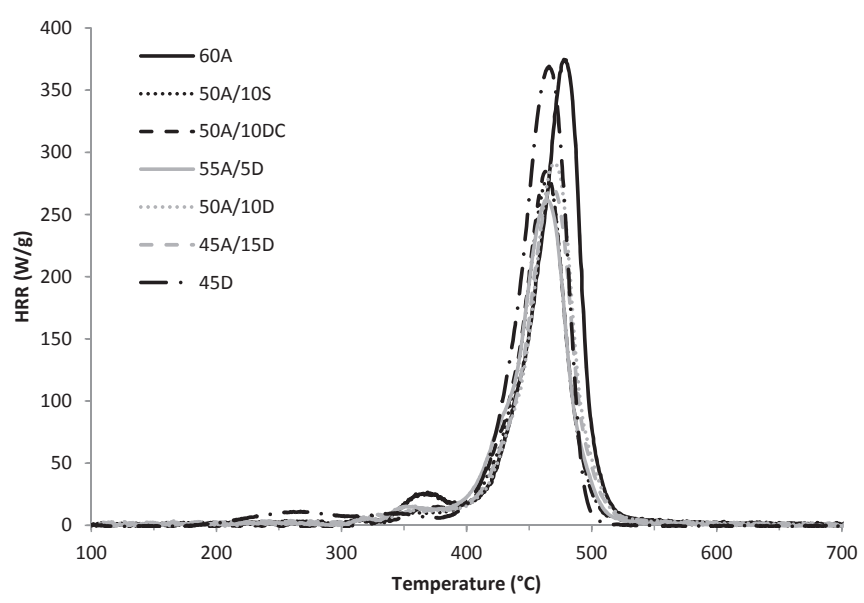

Fig. 21. PCFC curves for the formulations containing ATH and silica-based fillers.

degradation peak for composites containing a combination of ATH and silica-based filler appears at $300^{\circ} \mathrm{C}$. The maximum of the heat release is however more important in the case of the sample 60A. Concerning the main PHRR, the temperature of the beginning of heat release for the composites EVA/ATH/silica-based filler is similar as the temperature of the formulation $45 \mathrm{D}$ ( of about $455^{\circ} \mathrm{C}$ ).
This observation corresponds to the TGA results previously presented. PCFC tests were carried out with an FTIR coupling, using a Nicolet iS10 FT-IR (Thermo Scientific) device. There are two different degradation steps observed during the heat release variations. The Fig. 22 presents the FTIR analyses of the molecules obtained after the combustion of the gases of pyrolysis for the sample $45 \mathrm{D}$, released at $200{ }^{\circ} \mathrm{C}$.

The combination of a large peak at $2300 \mathrm{~cm}^{-1}$ and a fine peak at $700 \mathrm{~cm}^{-1}$ correspond to a $\mathrm{C}=\mathrm{O}$ bond of the $\mathrm{CO}_{2}$. The release of $\mathrm{CO}_{2}$ exists in the case of all the formulations. In the same way as the TGA and PCFC observations, the appearance of these peaks is related to a lower release temperature for the sample 45D. The presence of $\mathrm{CO}_{2}$ may be linked to the degradation of the side groups of the EVA, with the release of acetic acid degraded at the PCFC. The measurements show that the presence of diatomite in a large amount leads to the catalysis of the thermal decomposition of the EVA.

In the case of the combination of ATH and diatomite, the earlier release of acetic acid is not observed. It is possible that the presence of ATH inhibits the catalytic effect.

The FTIR analysis of the species released at the beginning of the thermal degradation of the sample with $45 \mathrm{wt} \%$ of calcined diatomite $\left(250-300{ }^{\circ} \mathrm{C}\right)$ presents a similar spectrum as the sample 45D at $200{ }^{\circ} \mathrm{C}$. It seems that the calcined diatomite also catalyze the thermal degradation of the EVA, but not to the same extent. Due to the modifications of the fillers during the calcination, the porous structure of the diatomite seems to be the principal parameter leading to the catalytic effect observed. This also may be related to the accessibility and the concentration of the hydroxyl groups at the surface of the filler, or the presence of iron in the structure. More experimentations are needed to confirm these hypotheses, and particularly on other species of diatomite.

\section{Conclusion}

The synergistic effect of a pennate diatomite in EVA/ATH composites was studied, regarding the fire retardancy assessed by cone calorimeter tests. The incorporation of at least $5 \mathrm{wt} \%$ of crushed diatomite improves the fire behaviour. The presence of diatomite seems to improve the barrier effect by promoting the swelling of the sample, by formation of a solid foam-like structure. With $10 \mathrm{wt}$ $\%$ of diatomite, a distinct decrease in pHRR and an improved barrier effect due to an expanded cohesive layer were noticed. The incorporation of spherical-shape silica and calcined diatomite does not lead to efficient fire retardancy. As the calcination of diatomite leads to a sintering of its porous structure, it is proposed that the porosity of the diatomite has an influence the formation of an efficient barrier layer. Furthermore, it seems that the action of both ATH and diatomite is needed to form an expanded protective layer. Measurements carried out on an EVA containing only diatomite seem to confirm the presence of a catalytic effect on the degradation of the matrix. Indeed, in the sample 45D, the degradation of the EVA seems to occur at a lower temperature than the other samples, even pure EVA. Even if the presence of diatomite seems to improve the fire retardancy of an EVA composite, it could be useful carry out more fire testing. Indeed, cone calorimeter does not enable to study characteristics such as self-extinguishing or fire propagation. Due to the change of scale and experimental conditions, results does not always correlate from one test to another. Tests such as LOI or UL-94 could be used to confirm the role of the diatomite as a synergistic agent.

Rheometric measurements showed that an increase of viscosity leads to a decrease of the pHRR. A high viscosity can also be associated to the capacity of expansion of the sample, leading to a better barrier effect. Even if this second effect seems to act after the pHRR, the set-up of the barrier layer may also occur at the beginning of the 


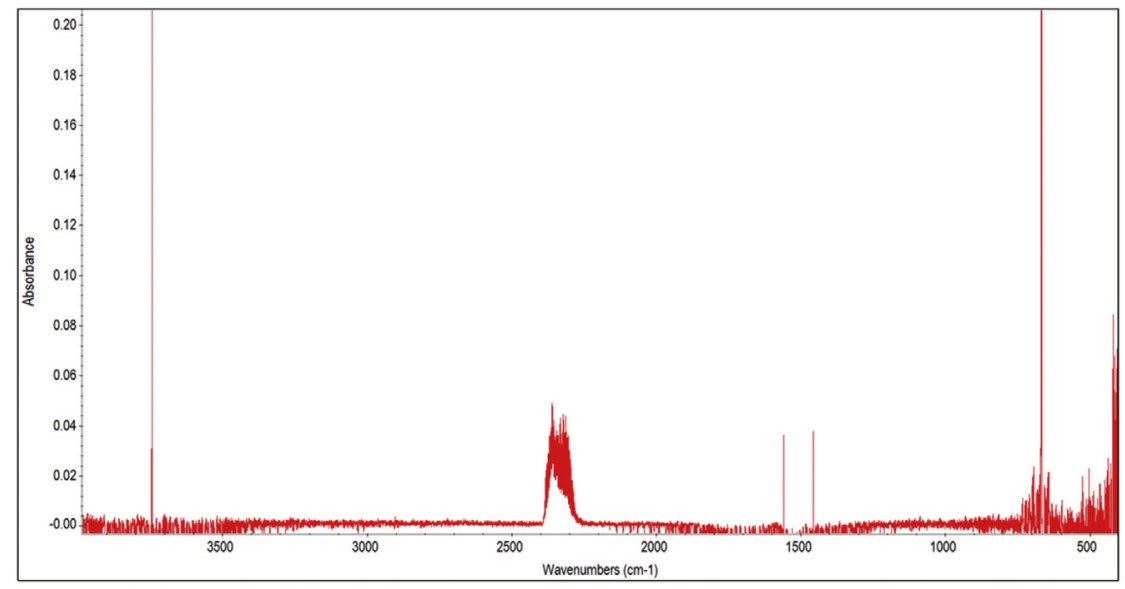

Fig. 22. FTIR spectrum of the compounds obtained after the combustion step during the PCFC analysis of the sample $45 \mathrm{D}$ (pyrolysis step between 200 and $300{ }^{\circ} \mathrm{C}$ ).

thermal degradation, reducing the pHRR. The use of calcined diatomite decreases the viscosity compared to the raw diatomite. The accessibility of the porosity seems to have a major influence on the role of the viscosity in fire retardancy. An optimum was found for the sample containing $10 \mathrm{wt} \%$ of diatomite. The observations concerning the influence of the viscosity on the fire behaviour of EVA/ATH/Diatomite samples match previous results on EVA/ATH/ Kaolinite samples. The viscosity of an EVA-based composite seems to be the key parameter acting on the pHRR during the cone calorimeter test, by the decrease of the bubbling at the surface of the sample. Furthermore, the high viscosity during the thermal degradation seems to influence the structure and the efficiency of the barrier effect in the second part of the cone calorimeter curve. It can also be assumed that these two phenomena are strongly related.

Flowing experiments confirm the results obtained with the ARES rheometer. The samples presenting a high viscosity form a solid foam-like structure during the fire, improving the thermal insulation. We assume that the gases of decomposition are confined longer inside the molten polymer, designing a structure conserved by the mineral fillers in the residue. A hypothesis may be that the good accessibility of the porous structure of diatomite, for the polymer chains, improves the interface between the matrix and the filler. Then, the network defined by the molten composite and the gases of decomposition acts as a template for the fillers. The expanded layer is then conserved, and the structure remains in the residue. Further experimentations are needed to refine this hypothesis.

\section{Acknowledgements}

The authors want to acknowledge Antoine DELAVAUD, Yohan DOURIN and Dongyi LI, students at the École des Mines d'Alès for their implication in the compilation and interpretation of the results.

\section{Appendix A. Supplementary data}

Supplementary data related to this article can be found at http:// dx.doi.org/10.1016/j.polymdegradstab.2016.04.018.

\section{References}

[1] C. Dearmitt, New ATH developments drive flame retardants cable compounding, Plast. Add. Compd. 4 (5) (2002) 12-14.

[2] E.E. McIlveen, Fire-retardant cable systems, Trans. Indus. Appl. IA-11 (3)
(1975).

[3] A.M. Henderson, Ethylene-vinyl acetate (EVA) copolymers: a general review, Electr. Insul. Mag. 9 (1) (1993) 30-38.

[4] W.E. Horn, Inorganic hydroxides and hydroxycarbonates: their function and use as flame retardants, in: Fire Retard. Polym. Mater, 2000, pp. 285-352.

[5] T.R. Hull, A. Witkowski, L. Hollingbery, Fire retardant action of mineral fillers, Polym. Degrad. Stab. 96 (8) (2011) 1462-1469.

[6] W. Zeng, N. Chen, Thermodynamic analysis of thermal decomposition of $\mathrm{Al}(\mathrm{OH})_{3}$, J. Mater. Sci. Technol. 13 (1997) 446.

[7] R.N. Rothon, P.R. Hornsby, Flame retardant effects of magnesium hydroxide, Polym. Degrad. Stab. 54 (1996) 383-385.

[8] R.N. Rothon, P.R. Hornsby, Fire retardant fillers for polymers, Polym. Green Flame Retard. (2014) 289-321.

[9] B. Schartel, M. Bartholmai, U. Braun, Barrier effects for the fire retardancy of polymers, in: Fire Retard. Polym.: New Appl. Miner. Fillers, 2005, pp. 264-275.

10] L. Delfosse, C. Baillet, A. Brault, D. Brault, Combustion of ethylene-vinyl acetate copolymer filled with aluminium and magnesium hydroxides, Polym. Degrad. Stab. 23 (4) (1989) 337-347.

[11] F. Cavodeau, R. Sonnier, B. Otazaghine, J.M. Lopez-Cuesta, C. Delaite, Ethylenevinyl acetate copolymer/aluminium trihydroxide composites: a new method to predict the barrier effect during cone calorimeter tests, Polym. Degrad. Stab. 120 (2015) 23-31.

[12] F. Laoutid, L. Ferry, E. Leroy, J.M. Lopez-Cuesta, Intumescent mineral fire retardant systems in ethylene-vinyl acetate copolymer: effect of silica particles on char cohesion, Polym. Degrad. Stab. 91 (9) (2006) 2140-2145.

[13] C. Feng, M. Liang, W. Chen, J. Huang, H. Liu, Flame retardancy and thermal degradation of intumescent flame retardant EVA composite with efficient charring agent, J. Anal. Appl. Pyrol. (2015) 1-8.

[14] N.D. Zaharri, N. Othman, Z.A.M. Ishak, Thermal and mechanical properties of zeolite filled ethylene vinyl acetate composites, Procedia Chem. 4 (2012) 95-100.

[15] M.A. Cárdenas, D. García-López, I. Gobernado-Mitre, J.C. Merino, J.M. Pastor, J.D.D. Martínez, J. Barbeta, D. Calveras, Mechanical and fire retardant properties of EVA/clay/ATH nanocomposites: effect of particle size and surface treatment of ATH filler, Polym. Degrad. Stab. 93 (11) (2008) 2032-2037.

[16] G. Huang, Z. Fei, X. Chen, F. Qiu, X. Wang, J. Gao, Functionalization of layered double hydroxides by intumescent flame retardant: preparation, characterization, and application in ethylene vinyl acetate copolymer, Appl. Surf. Sci. 258 (24) (2012) 10115-10122.

[17] D.Y. Wang, X.X. Cai, M.H. Qu, Y. Liu, J.S. Wang, Y.Z. Wang, Preparation and flammability of a novel intumescent flame-retardant poly(ethylene-co-vinyl acetate) system, Polym. Degrad. Stab. 93 (12) (2008) 2186-2192.

[18] R. Sonnier, L. Ferry, C. Longuet, F. Laoutid, B. Friederich, A. Laachachi, J.M. Lopez-Cuesta, Combining cone calorimeter and PCFC to determine the mode of action of flame-retardant additives, Polym. Adv. Technol. 22 (7) (2011) 1091-1099.

[19] S. Bourbigot, M. Le Bras, R. Leeuwendal, K.K. Shen, D. Schubert, Recent advances in the use of zinc borates in flame retardancy of EVA, Polym. Degrad Stab. 64 (1999) 419-425.

[20] T. Olcese, C. Pagella, Vitreous fillers in intumescent coatings, Prog. Org. Coat. 36 (4) (1999) 231-241.

[21] C. Mark, N. Sidney, M. Rodrı, M. Edge, E. Fontan, Degradation and stabilisation of poly (ethylene-stat-vinyl acetate): 1-spectroscopic and rheological examination of thermal and thermo-oxidative degradation mechanisms, Polym. Degrad. Stab. 91 (2006) 154-164.

[22] A. Marcilla, A. Gómez, S. Menargues, J. García-Martínez, D. Cazorla-Amorós, Catalytic cracking of ethylene-vinyl acetate copolymers: comparison of different zeolites, J. Anal. Appl. Pyrol. 68-69 (2003) 495-506.

[23] Y.Y. Yen, H.T. Wang, W.J. Guo, Synergistic flame retardant effect of metal 
hydroxide and nanoclay in EVA composites, Polym. Degrad. Stab. 97 (6) (2012) 863-869.

[24] M. Fu, B. Qu, Synergistic flame retardant mechanism of fumed silica in ethylene-vinyl acetate/magnesium hydroxide blends, Polym. Degrad. Stab. 85 (2004) 633-639.

[25] H. Huang, M. Tian, L. Liu, Z. He, Z. Chen, L. Zhang, Effects of silicon additive as synergists of $\mathrm{Mg}(\mathrm{OH})_{2}$ on the flammability of ethylene vinyl acetate copolymer, J. Appl. Polym. Sci. 99 (6) (2006) 3203-3209.

[26] S. Sabater, Diatoms, in: Encycl. Inland Waters, 2009, pp. 149-156.

[27] P. Moyle, D. Thomas, With or without salt: a comparison of marine and continental-lacustrine diatomite deposits, in: Contributions Indus. Miner. Res, 2003.

[28] N. Ediz, I. Bentli, I. Tatar, Improvement in filtration characteristics of diatomite by calcination, Intern. J. Min. Process 94 (3-4) (2010) 129-134.

[29] Z. Korunic, Review: diatomaceous earths, a group of natural insecticides, J. Stored Prod. Res. 34 (2) (1998) 87-97.

[30] F. Akhtar, Y. Rehman, L. Bergström, A study of the sintering of diatomaceous earth to produce porous ceramic monoliths with bimodal porosity and high strength, Powder Technol. 201 (3) (2010) 253-257.

[31] R. Sonnier, A. Viretto, L. Dumazert, M. Longery, S. Buonomo, B. Gallard, C Longuer, F. Cavodeau, R. Lamy, A. Freitag, Conditions of synergism between trihydroxyde aluminum and silica in EVA copolymer, submitted in: Polym. Degrad. Stab.

[32] R.E. Lyon, R.N. Walters, Pyrolysis combustion flow calorimetry, J. Anal. Appl. Pyrol. 71 (1) (2004) 27-46.

[33] T. Kashiwagi, M. Mu, K. Winey, B. Cipriano, S.R. Raghavan, S. Pack M. Rafailovich, Y. Yang, E. Grulke, J. Shields, R. Harris, J. Douglas, Relation between the viscoelastic and flammability properties of polymer nanocomposites, Polymer 49 (2008) 4358-4368.
[34] L. Clerc, L. Ferry, E. Leroy, J.M. Lopez-Cuesta, Influence of talc physical properties on the fire retarding behaviour of (ethylene-vinyl acetate copolymer/ magnesium hydroxide/talc) composites, Polym. Degrad. Stab. 88 (3) (2005) 504-511.

[35] M. Batistella, B. Otazaghine, R. Sonnier, A.S. Caro-Bretelle, C. Petter, J.M. LopezCuesta, Fire retardancy of ethylene vinyl acetate/ultrafine kaolinite composites, Polym. Degrad. Stab. 100 (2014) 54-62.

[36] J. Rouquerol, D. Avnir, C.W. Fairbridge, D.H. Everett, J.H. Haynes, N. Pernicone, J.D.F. Ramsay, K.S.W. Sing, K.K. Unger, Recommendations for the characterization of porous solids, Pure Appl. Chem. 66 (8) (1994) 1739-1758.

[37] P. Llewellyn, J. Rouquerol, L. Luciani, R. Denoyel, Texture des matériaux pulvérulents ou poreux, in: Techniques de l'Ingénieur, vol. 33, 2003.

[38] G. Hu, K. Dam-Johansen, S. Wedel, J.P. Hansen, Decomposition and oxidation of pyrite, Prog. Energy Combust. Sci. 32 (3) (2006) 295-314.

[39] G.V. Chilingar, H.J. Bissell, K.H. Wolf, Diagenesis of carbonate sediments and epigenesis (or catagenesis) of limestones, Dev. Sedimentol. 25 (1979) $247-422$.

[40] M. Batistella, A.S. Caro-Bretelle, B. Otazaghine, P. Ienny, R. Sonnier, C. Petter, J.M. Lopez-Cuesta, The influence of dispersion and distribution of ultrafine kaolinite in polyamide- 6 on the mechanical properties and fire retardancy, Appl. Clay Sci. 116-117 (2015) 8-15.

[41] A.V. Shenoy, Rheology of Filled Polymer Systems, 2013.

[42] S.D.C. Guerreiro, I.M. João, L.E.P. Real, Evaluation of the influence of testing parameters on the melt flow index of thermoplastics, Polym. Test. 31 (8) (2012) 1026-1030.

[43] R. Sonnier, G. Dorez, H. Vahabi, C. Longuet, L. Ferry, FTIR-PCFC coupling: A new method for studying the combustion of polymers, Combust. Flame 161 (5) (2014) 1398-1407. 